\title{
Kerosene-fueled supersonic combustion modeling based on skeletal mechanisms
}

\author{
Wei Yao ${ }^{1,2}$
}

Received: 2 April 2019 / Revised: 24 June 2019 / Accepted: 14 July 2019 / Published online: 9 September 2019

(C) The Chinese Society of Theoretical and Applied Mechanics and Springer-Verlag GmbH Germany, part of Springer Nature 2019

\begin{abstract}
A brief review of the recent advances in kerosene-fueled supersonic combustion modeling is present by comparing the fuels, reviewing the kinetic mechanisms, and introducing recent modeling results. The advantages and disadvantages of hydrogen and kerosene for the scramjet combustor are compared to show that kerosene is a more viable fuel option for a Mach number range of 4-8. However, detailed kinetic mechanisms for kerosene, which usually contain thousands of elementary reactions, must be significantly reduced for use in modeling. As of this writing, the smallest skeletal kerosene mechanism has only 19 species and 53 reversible reactions. In contrast to pioneer models based on global chemistry, the current kerosene-fueled supersonic combustion models based on reduced/skeletal chemistry are classified as second-stage. The influence of kinetic mechanisms, global equivalence ratios, inlet Mach number, geometric shape, and domain symmetry are reviewed based on high-fidelity models and available measurements. With the advances in computational technology, models with accurate descriptions of both flow and chemistry are becoming a promising, indispensable approach for the study of supersonic combustion.
\end{abstract}

Keywords Kerosene $\cdot$ Supersonic combustion $\cdot$ Large eddy simulation $\cdot$ Skeletal mechanism $\cdot$ Scramjet

\section{Introduction}

The research on supersonic combustion has a rather long history over 60 years, during which the promise of hypersonic flight has both challenged and disheartened researchers. To date, although numerous hypersonic concepts, e.g., scramjet, rocket, and turbojet, have been proposed and tested, no sophisticated air-breathing vehicles capable of speeds greater than a Mach number $(\mathrm{Ma})$ of 5 have been manufactured. Attractive future propulsion solutions for hypersonic vehicles may require a combined-cycle system, composed of scramjet, rocket, and turbojet [1]. Consequently, most importantly, the fuel selection should satisfy the requirements for a broad range of propulsion systems. Fuel serves as the source of energy during combustion and as a coolant. Fuel plays an

Wei Yao

weiyao@imech.ac.cn

1 Key Laboratory of High-Temperature Gas Dynamics, Institute of Mechanics, Chinese Academy of Science, Beijing 100190, China

2 School of Engineering Science, University of Chinese Academy of Science, Beijing 100049, China important role in determining the engine's range potential, operability, system maintenance requirements, and safety. Beginning in the early 1950s, the United States embarked on research on hydrogen fuel supersonic combustion, which then blossomed during the execution of the National AeroSpace Plane (NASP) program from 1987 to 1995, and peaked in 2004 with the successful flight test of the cryogenic hydrogen-fueled X-43A hypersonic vehicle. In parallel with the study of hydrogen-fueled supersonic combustion, research on hydrocarbon-fueled supersonic combustion was carried out intermittently. After the termination of NASP, the US Air Force devoted its efforts to research on hydrocarbonfueled supersonic combustion. The most important characteristics determining fuel selection are the heat of combustion, the reaction rate, and the heat capacity (cooling capability), along with cost and safety. Table 1 compares several properties of typical aviation fuels. As can be seen, hydrogen has the advantage of high reaction rate (three orders of magnitude higher than that of kerosene), high specific impulse (three times that of kerosene), and high heat sink (6.5 times that of kerosene), which makes it an ideal fuel for trans-atmospheric vehicles. However, the energy density per unit volume of liquid hydrogen is significantly lower than (one-quarter of) that 
Table 1 Selected properties of typical jet fuels

\begin{tabular}{lllllll}
\hline Fuel & Formula & $\begin{array}{l}\text { Ignition delay } \\
(\mathrm{ms})\end{array}$ & $\begin{array}{l}\text { Heat of combustion } \\
\left(\mathrm{MJ} \cdot \mathrm{kg}^{-1}\right)\end{array}$ & $\begin{array}{l}\text { Heat sink } \\
\left(\mathrm{kJ} \cdot \mathrm{kg}^{-1} \cdot \mathrm{K}^{-1}\right)\end{array}$ & $\begin{array}{l}\text { Flash point } \\
(\mathrm{K})\end{array}$ & $\begin{array}{l}\text { Density } \\
\left(\mathrm{kg} \cdot \mathrm{m}^{-3}\right)\end{array}$ \\
\hline Liquid hydrogen & $\mathrm{H}_{2}$ & $\sim 10^{3}$ & 141.8 & 14.42 & Gaseous & 70.0 \\
Liquid methane & $\mathrm{CH}_{4}$ & $\sim 0.1$ & 55.5 & 2.23 & 85 & 422.6 \\
Jet-A1 & $\mathrm{C}_{12} \mathrm{H}_{23}$ & $\sim 1$ & 46.2 & 2.30 & 311 & 840.0 \\
\hline
\end{tabular}

of kerosene, thus precluding its use for atmospheric vehicles because of the drastic increase in drag. Moreover, the high production cost of hydrogen compared with that of fossil fuels (around tenfold higher) — not to mention the storage and maintenance costs-limits the use of hydrogen to specialty applications. Because of the much higher volumetric energy density and economic benefits, hydrocarbon fuels are more competitive than cryogenic hydrogen for hypersonic air-breathing propulsion systems [2]. Around 5.8\% of total oil production worldwide is consumed by the aviation sector [3]. Jet fuels also have higher flash points, which makes them less flammable and therefore safer during transport and storage. Although hydrogen will have an irreplaceable role in future studies of trans-atmospheric flight with $M a>10$, it does not have an obvious advantage with $M a<8$, which is the main battlefield of short-term military applications. Methane is applicable for $M a=8-10$, and kerosene is a more viable fuel option for $M a=4-8$.

Despite the recognized benefits of jet fuels for hypersonic applications, there are a number of shortcomings which become especially detrimental for $M a>6$, i.e., slower reaction rate, poorer specific impulse, lower heat sink, and lower thermal stability. In particular, additional atomization and gasification are needed before the liquid kerosene can be mixed with the oxidizer to form a combustible gas. For these, special refinements and additives are required to adjust the freezing points, the flash point, and the combustion performance. For example, the specific low-volatility jet fuel JP-7 was developed for the SR-71 Blackbird supersonic military aircraft via the addition of fluorocarbons and oxidizing agents. In 2013, a successful flight test of the X-51A demonstrated that the shortcomings of jet fuels could be overcome to some extent.

Given the limited use of experimental measures in hypersonic flows, computational fluid dynamics (CFD) has become a necessary analytical technique in the modeling of supersonic combustion. Complex unsteady phenomena such as the subtle flame-turbulence interactions can only be well understood by giving access to local and instantaneous data. With the advances in massively parallel computing, high-fidelity modeling of supersonic combustion is now achievable. The modeling of kerosene-fueled supersonic combustion in a scramjet combustor is a challenging multi-physics problem, which involves complex atomization, evaporation, chemistry with hundreds of species and thou- sands of reactions, and high Reynolds number $(R e) \sim \mathrm{O}\left(10^{6}\right)$ turbulence.

The residence time in hypersonic combustors is limited to the order of fractions of a millisecond, which is commensurate with the chemical timescale of kerosene combustion. This poses two salient challenges: (1) achieving ignition in the short residence times available is difficult, and (2) the complex turbulence-chemistry interaction cannot be described by computationally efficient fast-chemistryassumed combustion models. A clear understanding of combustion chemistry and high-fidelity modeling are necessary for the development of highly reactive jet fuels. However, the detailed reaction mechanisms of kerosene usually contain thousands of elementary reactions, which make them computationally unfeasible at present when coupled with multidimensional flow modeling. In addition to accurate knowledge of the chemical kinetics, predictive modeling of thermochemical status over a wide temperature and pressure range is indispensable for kerosene, which is a complex compound involving thousands of species. Physical surrogates and reduced chemical mechanisms with an acceptable level of tractability must be developed to accurately reproduce the global predictions in concert with fluid dynamics models.

\section{Status of kerosene kinetic modeling}

Kerosene is a complex mixture with over 1000 hydrocarbons containing from 8 to 16 carbon atoms. Moreover, for any specific jet fuel, the chemical composition may differ significantly from one production location to another, with the average chemical formula ranging from $\mathrm{C}_{10.9} \mathrm{H}_{20.9}$ to $\mathrm{C}_{12} \mathrm{H}_{23}$ for Jet A, Jet A-1, TR0, and JP8 [4]. Because of its compositional complexity, kerosene must be modeled by a surrogate, which is defined as a mixture of a limited number (usually $<10$ ) of species with formulated fractions to best match real fuel properties, such as physical properties, chemical properties, or both. Most surrogate models were developed based on the experimental data of Jet-A and JP-8 [5]. During the last decade, a single-component surrogate was often used [6-8]. Possibly the first threecomponent surrogate was developed by Guéret et al. [9] for Jet $\mathrm{A}-1$ as a mixture of $79 \mathrm{wt} \% n$-undecane, $10 \mathrm{wt} \%$ $n$-propylcyclohexane, and $11 \mathrm{wt} \%$ 1,2,4-trimethylbenzene. 
Subsequently, Schulz [10], Heneghan et al. [11], Violi et al. [12], Cooke et al. [13], Agosta [14], and Humer et al. [15] developed surrogate blends for JP-8 with $12,12,6,6,5$, and 3 hydrocarbons, respectively. A surrogate for JP-7 was developed by Daniau et al. [16] using $n$-dodecane directly. Four surrogate model fuels for Jet A-1 were proposed by Dagaut et al. [17], which included pure $n$-decane (100 mol\%), $n$-decane/n-propylbenzene (74/26 mol\%), $n$-decane/n-propylcyclohexane $(74 / 26 \mathrm{~mol} \%)$, and $n$ decane/n-propylbenzene/ $n$-propylcyclohexane $\quad(74 / 15 / 11$ mol\%), among which the three-component surrogate was found to be the most appropriate. A simplified surrogate was suggested by Colket et al. [18] that was composed of $n$-decane (50 vol\%), $n$-butylcyclohexane (25 vol\%), and $n$-butylbenzene ( $25 \mathrm{vol} \%)$, which were shown to be more reactive and difficult to extinguish than typical jet fuels (Jet-A and JP-8). A so-called Aachen surrogate for Jet-A was proposed by Honnet et al. [19] that consisted of $n$-decane $80 \mathrm{wt} \%$ and 1,2,4-trimethylbenzene $20 \mathrm{wt} \%$. In their study, Lindstedt and Maurice [20] proposed twocomponent surrogate blends comprising $89 \mathrm{~mol} \%$ n-decane and $11 \mathrm{~mol} \%$ aromatic fuel, where the aromatic component could be represented by benzene, toluene, ethylbenzene, and ethylbenzene/naphthalene. In another work, Dooley et al. derived three-component [21] and four-component [22] surrogate fuels by constraining the mixtures of $n$-decane/iso-octane/toluene $\quad(42.67 / 33.02 / 24.31 \mathrm{~mol} \%)$ and $\quad n$-dodecane/iso-octane/1,3,5-trimethylbenzene/npropylbenzene $(40.41 / 29.48 / 7.28 / 22.83 \mathrm{~mol} \%)$ to reproduce the hydrogen/carbon ratio, derived cetane number $(\mathrm{DCN})$, and threshold sooting index (TSI) of Jet-A. Of note, the sooting behavior of aviation kerosene was successfully modeled by Moss and Aksit [23] using a pre-vaporized surrogate fuel blend of $77 \mathrm{vol} \% n$-decane and $23 \mathrm{vol} \%$ mesitylene. Blends of $n$ - and iso-alkane components were employed by Naik et al. [24] as surrogates for Fischer-Tropsch (F-T)-derived and biomass-derived jet fuels, while Mzé-Ahmed et al. [25] proposed a four-component surrogate fuel mixture, i.e., $n$-decane $(47.2 \mathrm{~mol} \%)$, isooctane (15.5 mol\%), n-propylcyclohexane (42.2 mol\%), and $n$-propylbenzene $(12.2 \mathrm{~mol} \%)$, for the oxidation of coal-to-liquid (CtL) synthetic jet fuel. Similarly, for the oxidation of gas-to-liquid (GtL) synthetic jet fuel, Dagaut et al. [26] proposed a widely used three-component surrogate consisting of iso-octane $(33.2 \mathrm{~mol} \%), n$-decane (57.7 $\mathrm{mol} \%)$, and $n$-propylcyclohexane $(9.1 \mathrm{~mol} \%)$. Studies by both Mzé-Ahmed et al. [25] and Dagaut et al. [26] revealed that the ignition behavior of the surrogate fuel was influenced mainly by $n$-alkanes and not by the addition of iso-alkanes and cyclo-alkanes (naphthenes). To remedy this, improved surrogate models for $\mathrm{GtL}$ and $\mathrm{CtL}$ fuels have been proposed [27] to achieve a more realistic representation of the iso-alkane, naphthene, and aromatic families, as follows: (1) GtL represented by a mixture of $n$-decane (28.1 wt $\%$ ), 2-methylheptane (30 wt\%), 3-methylheptane (33.1 wt $\%$ ), and Decalin (8.8 wt\%); and (2) CtL represented by a mixture of $n$-decane $(5.7 \mathrm{wt} \%)$, iso-octane $(11.5 \mathrm{wt} \%)$, 3-methylheptane (24.8 wt\%), n-propylcyclohexane (16.1 wt $\%$ ), Decalin (28.3 wt $\%$ ), $n$-propylbenzene (4 wt $\%$ ), and Tetralin (9.6 wt\%). Chromatographic analysis of China Daqing RP-3 aviation kerosene showed that its volume composition was $92.5 \mathrm{vol} \%$ saturated hydrocarbons, 0.5 vol\% unsaturated hydrocarbons, and $7 \mathrm{vol} \%$ aromatic hydrocarbons, which is close to Jet-A1. Based on this, Fan and Yu [28] proposed a three-component Daqing RP-3 surrogate with $n$-decane (49 mol\%), 1,3,5-trimethylcyclohexane (44 $\mathrm{mol} \%$ ), and $n$-propylbenzene (7 $\mathrm{mol} \%$ ).

Comprehensive kinetic modeling of kerosene combustion was described by Dagaut and Cathonnet [4]. Indeed, most of the kinetic mechanisms of kerosene are developed by assembling the individual mechanisms for all the surrogate components. For example, a 168-species/1089-reaction (168s/1089r) mechanism for RP-3 was recently developed [29] via the combination and duplication elimination of the combustion mechanisms of $n$-decane, $n$-dodecane, ethycyclohexane, and $p$-xylene. In some cases, sub-mechanisms for the formation of $\mathrm{NO}_{x}$, polycyclic aromatic hydrocarbons (PAH), and soot have been merged into the master mechanisms for pollutant prediction. For combustion applications in propulsion systems, high-temperature (>1000 K) kinetics are usually more relevant; therefore, low-temperature chemistry can be omitted to reduce the mechanism size without significant loss of accuracy. Even so, the detailed mechanisms based on surrogate hydrocarbons typically contain at least hundreds of elementary reactions. One of the earliest kerosene oxidation kinetics, proposed by Dagaut et al. [30] based on a single-component surrogate ( $n$-decane), includes 573 elementary reactions, most of them reversible, among 90 chemical species. Mechanism size grows with time, as discoveries in kinetic paths are continuously being made. A later detailed mechanism proposed by Dagaut and his group involves 298 species/2352 reactions [31] and 298 species/2352 reactions [17] by merging the kinetic reaction mechanisms proposed for the oxidation of each surrogate hydrocarbon. A more comprehensive detailed mechanism with 2185 species and 8217 reactions was subsequently developed by Mzé-Ahmed et al. [25] and Dagaut et al. [26] for GtL-fuel oxidation. The most recent detailed chemical kinetic reaction mechanism developed by Dagaut et al. [27] has been further expanded to include 2430 species reacting in 10,962 reversible reactions, which has been extensively validated using the entire experimental database collected by the Centre National de la Recherche Scientifique (CNRS, France). The detailed mechanism proposed by Naik et al. [24] for FT- and biomass-derived jet fuels consists of a total of 753 species and 4668 reactions. Based on a proposed six- 
Table 2 Typical mechanism sizes of different fuels

\begin{tabular}{llllll}
\hline Fuel/oxidizer & $\mathrm{H}_{2} /$ air & $\mathrm{CH}_{4} /$ air & $\mathrm{C}_{2} \mathrm{H}_{4} /$ air & $\mathrm{C}_{10} \mathrm{H}_{22} /$ air & Kerosene/air \\
\hline Number of species & 9 & 53 & 52 & 234 & 2185 \\
Number of reactions & 20 & 325 & 367 & 1452 & 8217 \\
\hline
\end{tabular}

component surrogate model, Cooke et al. [13] developed a semi-detailed kinetic mechanism composed of 221 gaseous species participating in 5032 reactions. Obviously, the size of these detailed mechanisms is prohibitively large for application to three-dimensional (3-D) models.

Modeling difficulty increases markedly as the mechanism size increases. As seen from Table 2, mechanism size increases significantly with fuel molecular weight. Carbonfree hydrogen has the smallest mechanism size, while typical mechanisms for $\mathrm{C}_{1}$ (carbon number is 1 ) and $\mathrm{C}_{2}$ species consist of species with numbers less than 100 . The mechanisms for realistic engine fuels with $\mathrm{C}>7$ usually consist of hundreds of species and thousands of reactions. The computational cost roughly scales with the square of the species number [32]; thus it is clear that computation using a detailed kerosene mechanism is time-consuming even for zero-dimensional (0-D) simulations.

Attempts have been made to develop global or quasiglobal kerosene mechanisms in order to simplify the modeling of combustion chemistry [33-41]. The earliest simple kinetic model for the combustion of kerosene is the one-step global reaction mechanism proposed by Najar and Goodger [34] based on a global surrogate of $\mathrm{C}_{13} \mathrm{H}_{24}$, and later modified by Aly and Salem [37] by adjusting the pre-exponential factor. Another one-step global mechanism was proposed by Westbrook and Dryer [36] using a global surrogate of $\mathrm{C}_{12} \mathrm{H}_{23}$.

Multiple-step quasi-global kinetic mechanisms usually consist of two parts: (1) a global pyrolysis reaction of kerosene into small-molecule hydrocarbons and (2) the global oxidation steps of small hydrocarbons. For example, a general quasi-global mechanism for aliphatic hydrocarbons was proposed by Hautman et al. [33] using $\mathrm{C}_{2} \mathrm{H}_{2}$ as the representative of pyrolyzed olefinic intermediates. In a method proposed by Gueret et al. [38], up to nine intermediates were used in a one-step pyrolysis reaction, and a detailed mechanism with 50 species and 360 reactions was then used for their oxidation. By combining the single-step pyrolysis reaction of $\mathrm{C}_{12} \mathrm{H}_{23}$ with the propane mechanism, Kundu and Deur [8] formulated an approximate Jet-A mechanism. The quasi-global mechanism proposed by Wang [39] includes two global reactions for the oxidation of kerosene, which is surrogated by the mixture of a paraffin and a cycloalkane but uses the same formula of $\mathrm{C}_{12} \mathrm{H}_{24}$, to $\mathrm{CO}$ and $\mathrm{H}_{2}$ (one for the paraffin fraction and one for the cycloalkane), and a 12-step $\mathrm{H}_{2} / \mathrm{CO} / \mathrm{O}_{2}$ reaction sub-mechanism. Another two-step quasi- global chemical scheme proposed by Franzelli et al. [40] consists of a kerosene pyrolysis reaction into $\mathrm{CO}$ and $\mathrm{H}_{2} \mathrm{O}$, and the $\mathrm{CO}$-to- $\mathrm{CO}_{2}$ equilibrium reaction, where it is claimed that the former controls the flame speed and the autoignition time, while the latter is necessary to correctly predict the flame temperature and the $\mathrm{CO}$ levels in the burnt gases. A 10-step quasi-global mechanism was recently developed by Choi [41] by formulating a global pyrolysis reaction of kerosene (surrogated by $\mathrm{C}_{10} \mathrm{H}_{20}$ ) into $\mathrm{CO}$ and $\mathrm{H}_{2}$, followed by oxidation reactions. Modeling tests in supersonic combustion by previous researchers [39, 42] and by the author's group show that the global mechanisms tend to predict a much more concentrated heat release, since the chemical timescale has been significantly underestimated, the flame temperature is overestimated by up to $1000 \mathrm{~K}$, and the flame stabilization is always in the jet-wake mode.

In sum, detailed mechanisms are too large to be applied, while global mechanisms have their inherent drawbacks; consequently, the development of reduced or skeletal mechanisms has attracted increasing attention over the past 5 years. Since 2014, Yao et al. [43-46] have released five versions of kerosene skeleton mechanisms, which have been extensively validated in large eddy simulation (LES) of realistic supersonic combustors [43-49]. Meanwhile, Liu et al. [50], Liu et al. [51], Zeng et al. [52, 53], Huang et al. [54], and Xu et al. [55] have developed combustion mechanisms with $41 \mathrm{~s} / 132$ r, $59 \mathrm{~s} / 158 \mathrm{r}, 50 \mathrm{~s} / 210 \mathrm{r}, 59 \mathrm{~s} / 180 \mathrm{r}$, and $138 \mathrm{~s} / 530 \mathrm{r}$, respectively, for China RP-3 kerosene, while Zettervall et al. [56], Strelkova et al. [57], and Slavinskaya [58] have proposed skeletal mechanisms for Jet-A with $22 \mathrm{~s} / 65 \mathrm{r}$, 24s/38r, and 40s/208r, respectively. Based on the concept of timescale separation, some algebraically reduced kerosene mechanisms have also been developed [59]. While the skeletal mechanisms have been significantly reduced from hundreds of species to only tens of species (e.g., from 2185 species $[25,26]$ to the current smallest 19 species [45]), a further reduction would be very difficult, and may be unnecessary, since the large errors induced no longer compensate for the small reduction in computational cost.

Figure 1 compares the predictions of ignition delay by different skeletal RP-3/Jet-A mechanisms under the same working conditions, i.e., $1 \mathrm{~atm}\left(1 \mathrm{~atm}=1 \times 10^{5} \mathrm{~Pa}\right)$ and unity equivalence ratio. Although these skeletal mechanisms are all developed for kerosene-type fuels, their kinetic properties may differ significantly for the following reasons: (1) they are based on different surrogate species; (2) they 


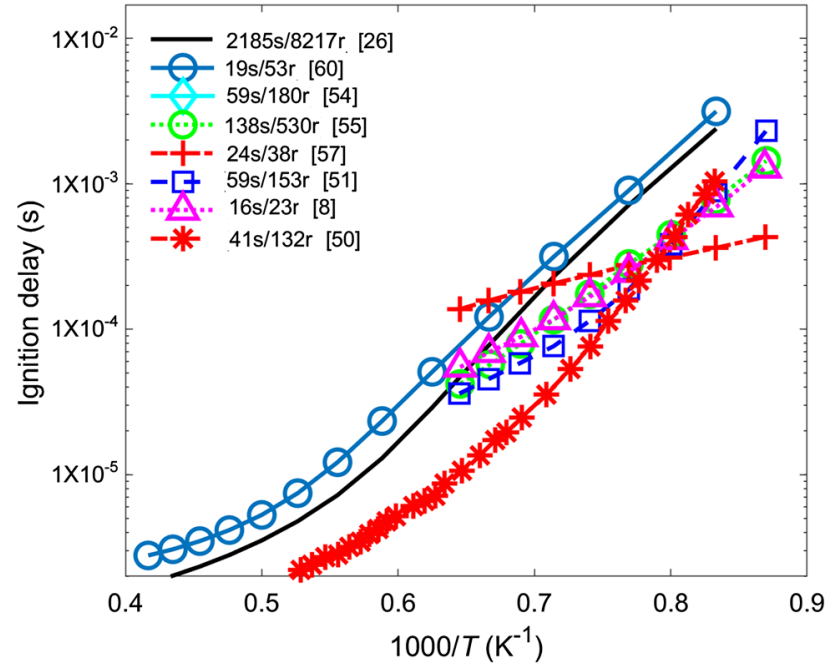

Fig. 1 Ignition delay predicted by Dagaut's detailed mechanisms [26] and the skeletal mechanisms developed by Yao et al. [60], Huang et al. [54], Xu et al. [55], Strelkova et al. [57], Liu et al. [51] and Kundu et al. [8], Liu et al. [50] under 1 atm and unity equivalence ratio

originate from different detailed mechanisms; and (3) they are developed and validated for different working conditions (e.g., different pressure and temperature ranges). For example, Yao's mechanism [60] is developed from Dagaut's detailed mechanism [26]; therefore, their predictions are highly consistent. The predictions are generally consistent in the high-temperature regime, but their deviations become larger in the low-temperature regime. As observed in the experiments, the surrogate composition would exert more influence on ignition delay below $1000 \mathrm{~K}$ [61].

In the series of studies conducted by Yao et al. [43], the detailed kerosene mechanism proposed by Dagaut et al. [26] with $2815 \mathrm{~s} / 8217 \mathrm{r}$ was reduced using the directed relation graph with error propagation and sensitivity analysis (DRGEPSA) [62] in combination with manual path analysis. To date, five versions of skeletal mechanisms, respectively 89s/668r [43], 48s/197r [44], 39s/153r [49], 28s/92r [46], and 19s/54r [45], have been developed. In these mechanisms, kerosene is surrogated by three components: $28.8 \mathrm{wt} \%$ iso-octane, $62.4 \mathrm{wt} \% n$-decane, and $8.8 \mathrm{wt} \%$ $n$-propylcyclohexane. The fidelity of these skeletal mechanisms has been validated based on a three-level framework [63] for typical ranges of working conditions in scramjet combustors [60], i.e., an equivalence ratio of $0.7-1.5$, static pressure of $0.5-3.0$ bar $\left(1 \mathrm{bar}=1 \times 10^{5} \mathrm{~Pa}\right)$, and static temperature of $300-3000 \mathrm{~K}$. In the base level of fidelity validation, the mechanisms were first validated for a wide range of kinetic properties based on 0-D and one-dimensional (1-D) ideal reactors, with little flow effects considered. The second level of fidelity validation mainly evaluated the predictive accuracy of time-averaged or statistical flow quantities by incorporating the mechanisms into 3-D flow models. The third level of fidelity validation evaluated the predictive accuracy of intermediate species and turbulence-chemistry interaction (TCI) modes, which are important measures in predicting transient turbulent combustion processes (e.g., ignition/extinction and flame stabilization). Figure $2 \mathrm{com}-$ pares the predictions of flame temperature, total heat release, ignition delay, laminar flame speed, and time-variant temperature and heat release rates among the five skeletal mechanisms. The predictions of the smallest $19 \mathrm{~s} / 53 \mathrm{r}$ mechanism are in reasonably good agreement with the original detailed mechanism. The skeletal mechanisms were further validated [60] at higher pressures to evaluate their suitability for rocket combustors. Figure 3 shows that the ignition delays predicted under pressures from 10 to 50 bar agree well with those predicted by the detailed mechanism.

\section{Recent advances in kerosene-fueled supersonic combustion modeling}

The typical operating range of scramjet combustors is $M a=$ 4-8 and altitude $H=16,000-26,000 \mathrm{~m}$ in the $M a-H$ map, most of which has been covered in the series of studies conducted by Yao et al. [43-49, 60, 64-70], as summarized in Table 3 and Fig. 4. Three geometric types of supersonic combustors were modeled, including the traditional rectangular combustor and two novel non-rectangular combustors: a round and an elliptical combustor. The inlet $M a$ ranged from 2 to 3, corresponding to the flight $M a$ from 4 to 7 . Fuellean and fuel-rich cases with global equivalence ratios from 0.6 to 1.4 were modeled for comparison.

\subsection{Influence of kinetic mechanisms}

Because of the lack of small-scale but high-fidelity kerosene mechanisms, kerosene-fueled supersonic combustion models are scarce in the literature. More than $80 \%$ of current supersonic combustion models are based on hydrogen fuel, e.g. those based on the HyShot I and II combustors [71-78], Scholar combustor [79-84], University of Virginia combustor [85], and University of Michigan combustor [86], with a small portion based on small-molecule hydrocarbon fuels (e.g. ethylene [86-89], methane [90, 91] and acetone [92]). Some attempts have been made to use large-molecule hydrocarbon fuels (e.g., $n$-decane $[93,94]$ ) to simulate the mixing and combustion of kerosene. Studies on kerosene-fueled supersonic combustion modeling have been very limited until recently, with pioneer studies by Rajasekaran and Babu [95] and Behera and Chakraborty [96], and a recent study by Lacaze et al. [97]. For the same reason (lack of reduced kerosene mechanisms), modeling of kerosene-fueled aeroengine combustors is also very scarce, with only some pioneer studies based on global or pre-tabulated chemistry 

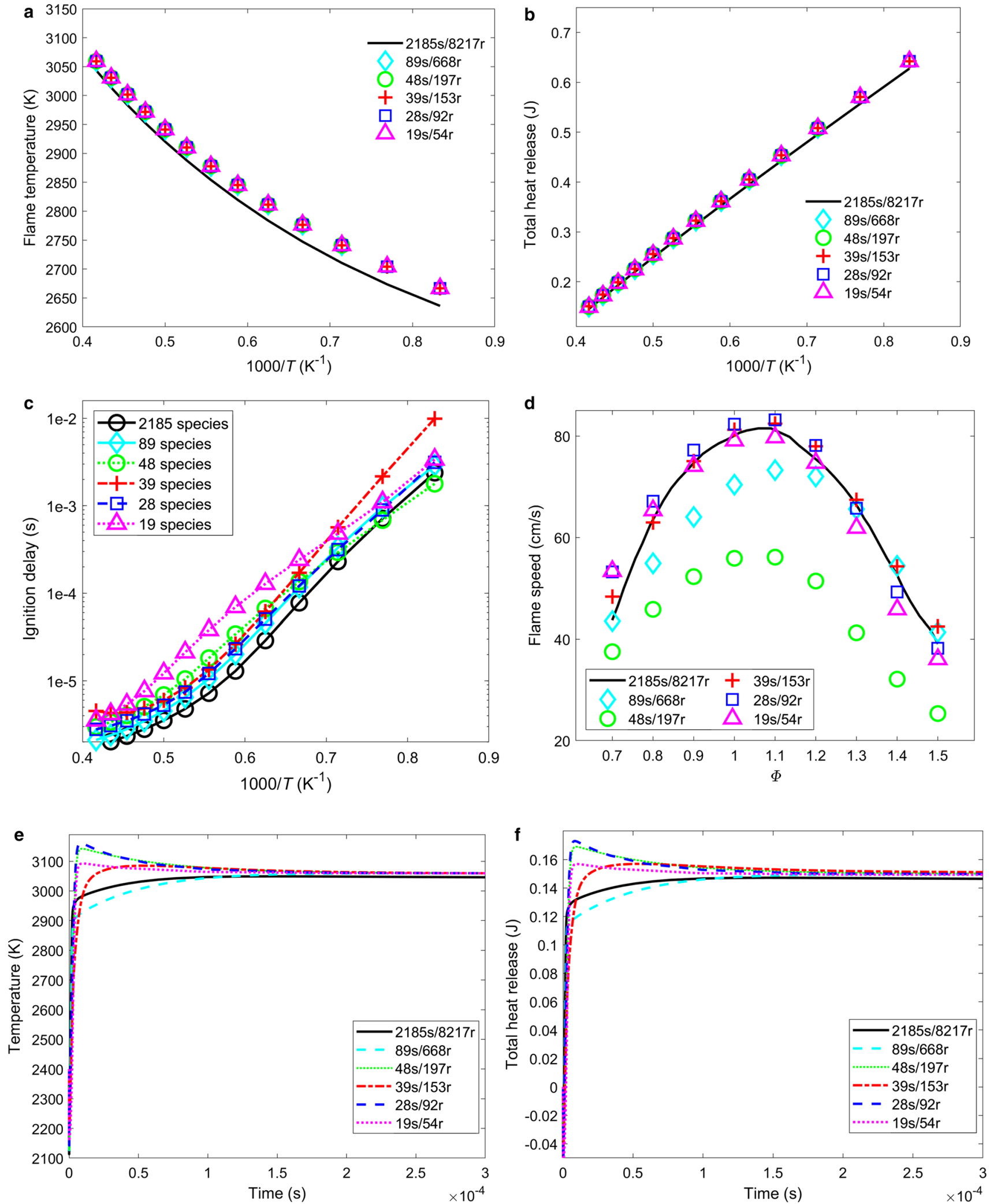

Fig. 2 Comparison of kinetic properties between different mechanisms for a flame temperature, $\mathbf{b}$ total heat release, $\mathbf{c}$ ignition delay in logarithmic ordinate, $\mathbf{d}$ laminar flame speed, e temperature, and $\mathbf{f}$ heat release (reprinted with permission from Ref. [43]) 

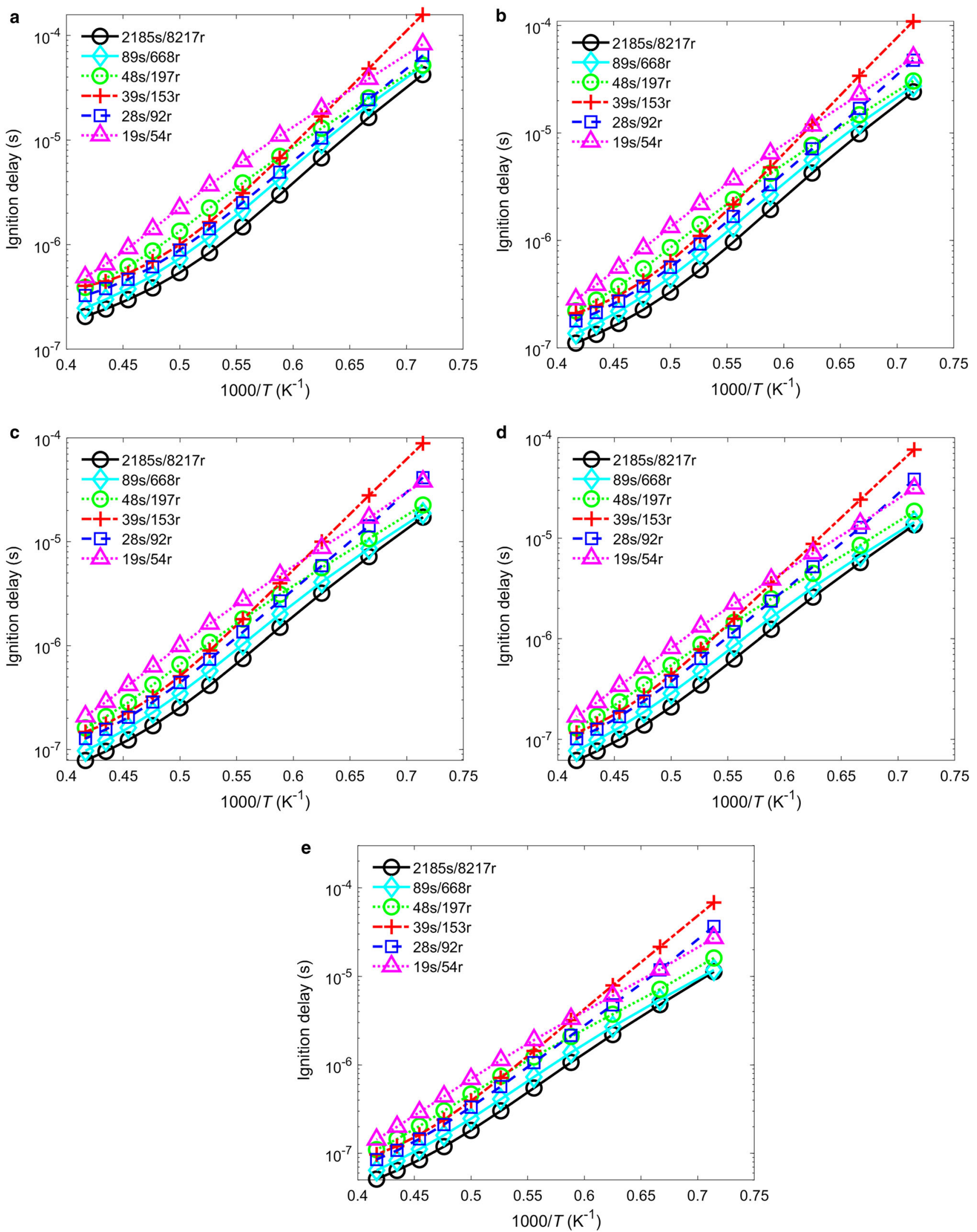

Fig. 3 Ignition delay predicted under a 10 bar, b 20 bar, c 30 bar, d 40 bar, e 50 bar 

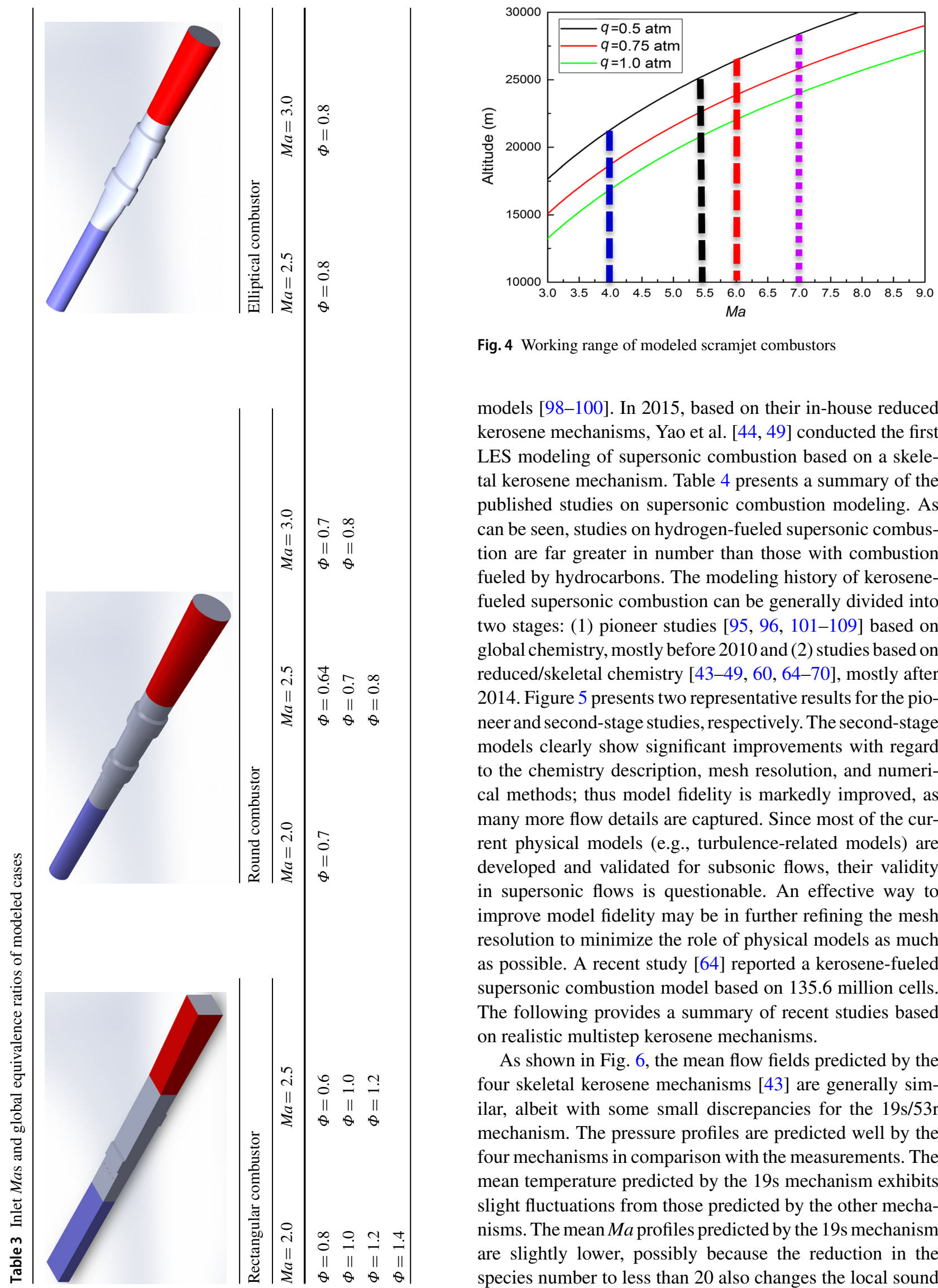

Fig. 4 Working range of modeled scramjet combustors

models [98-100]. In 2015, based on their in-house reduced kerosene mechanisms, Yao et al. [44, 49] conducted the first LES modeling of supersonic combustion based on a skeletal kerosene mechanism. Table 4 presents a summary of the published studies on supersonic combustion modeling. As can be seen, studies on hydrogen-fueled supersonic combustion are far greater in number than those with combustion fueled by hydrocarbons. The modeling history of kerosenefueled supersonic combustion can be generally divided into two stages: (1) pioneer studies [95, 96, 101-109] based on global chemistry, mostly before 2010 and (2) studies based on reduced/skeletal chemistry [43-49, 60, 64-70], mostly after 2014. Figure 5 presents two representative results for the pioneer and second-stage studies, respectively. The second-stage models clearly show significant improvements with regard to the chemistry description, mesh resolution, and numerical methods; thus model fidelity is markedly improved, as many more flow details are captured. Since most of the current physical models (e.g., turbulence-related models) are developed and validated for subsonic flows, their validity in supersonic flows is questionable. An effective way to improve model fidelity may be in further refining the mesh resolution to minimize the role of physical models as much as possible. A recent study [64] reported a kerosene-fueled supersonic combustion model based on 135.6 million cells. The following provides a summary of recent studies based on realistic multistep kerosene mechanisms.

As shown in Fig. 6, the mean flow fields predicted by the four skeletal kerosene mechanisms [43] are generally similar, albeit with some small discrepancies for the $19 \mathrm{~s} / 53 \mathrm{r}$ mechanism. The pressure profiles are predicted well by the four mechanisms in comparison with the measurements. The mean temperature predicted by the $19 \mathrm{~s}$ mechanism exhibits slight fluctuations from those predicted by the other mechanisms. The mean $M a$ profiles predicted by the $19 \mathrm{~s}$ mechanism are slightly lower, possibly because the reduction in the species number to less than 20 also changes the local sound 
Table 4 Literature statistics on supersonic combustion modeling

\begin{tabular}{|c|c|c|c|}
\hline Fuel & $\mathrm{H}_{2}$ & $\mathrm{C}_{2} \mathrm{H}_{4} / \mathrm{CH}_{4} / \mathrm{C}_{3} \mathrm{H}_{6} \mathrm{O}$ & Kerosene \\
\hline Number of studies & $>100$ & 5 & 11 (global chemistry) and 16 (redu \\
\hline $\mathbf{a}$ & & 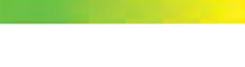 & $T(\mathrm{~K})$ \\
\hline b & & & $T(\mathrm{~K})$ \\
\hline & & & 650 \\
\hline
\end{tabular}

Fig. 5 Instantaneous temperature fields predicted by LES with a a global mechanism and 1 million cells (reprinted with permission from Ref. [103]), and b a 28s/92r skeletal mechanism and 49.22 million cells (reprinted with permission from Ref. [43])
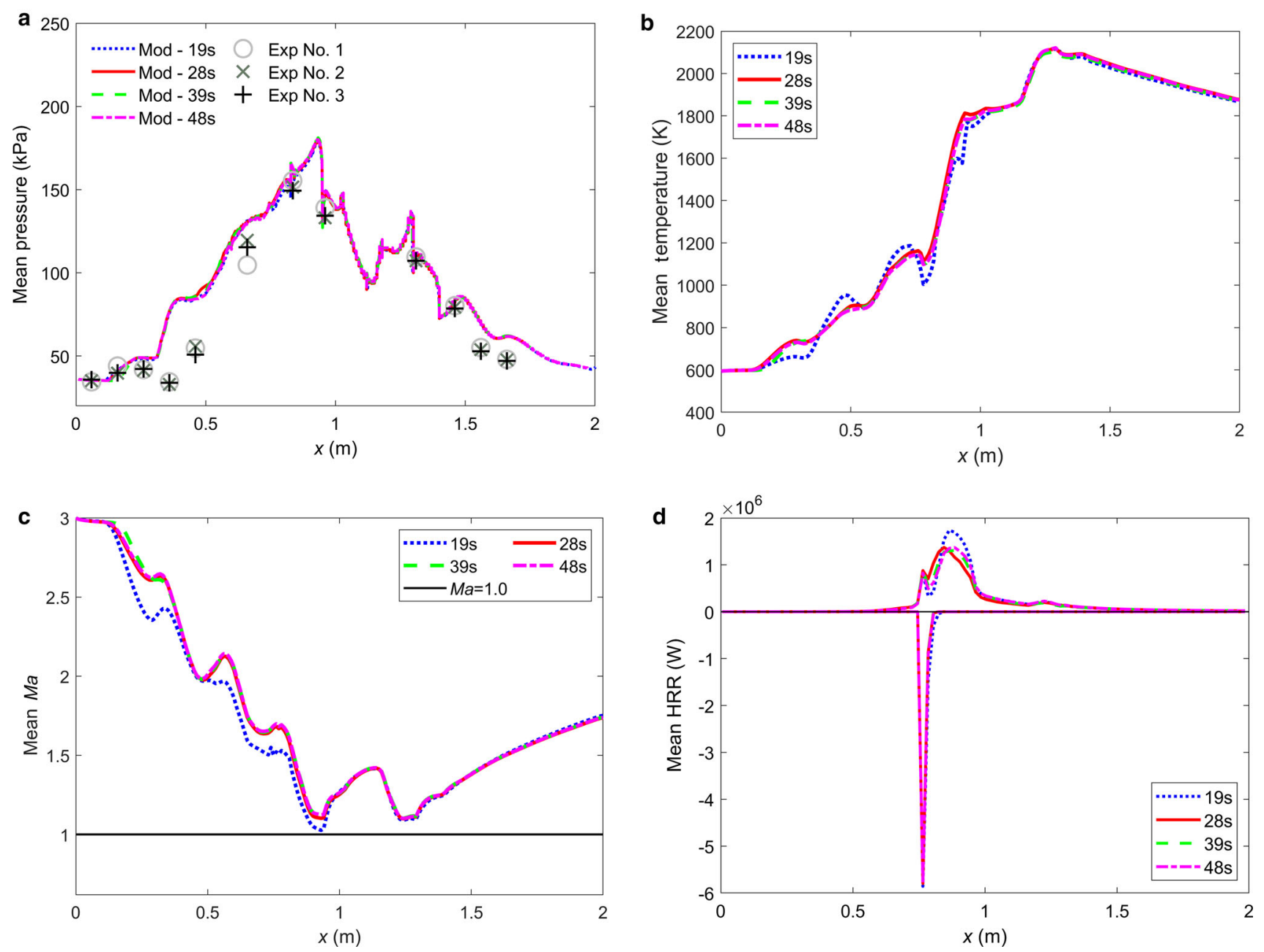

Fig. 6 Time-averaged a wall pressure, $\mathbf{b}$ temperature, $\mathbf{c} M a, \mathbf{d}$ heat release rate (HRR) predicted by different chemical mechanisms for an elliptical combustor (reprinted with permission from Ref. [43]) 

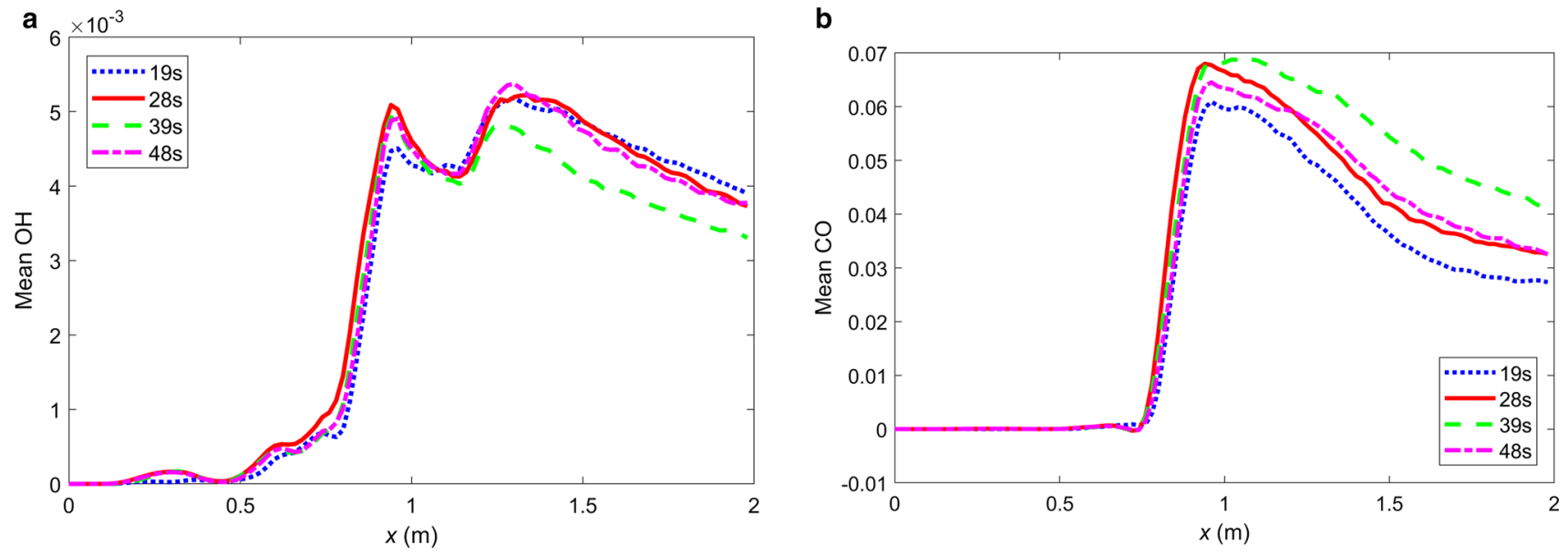

Fig. 7 Time-averaged mass fractions of $\mathbf{a} \mathrm{OH}$ and $\mathbf{b}$ CO predicted by different chemical mechanisms for an elliptical combustor
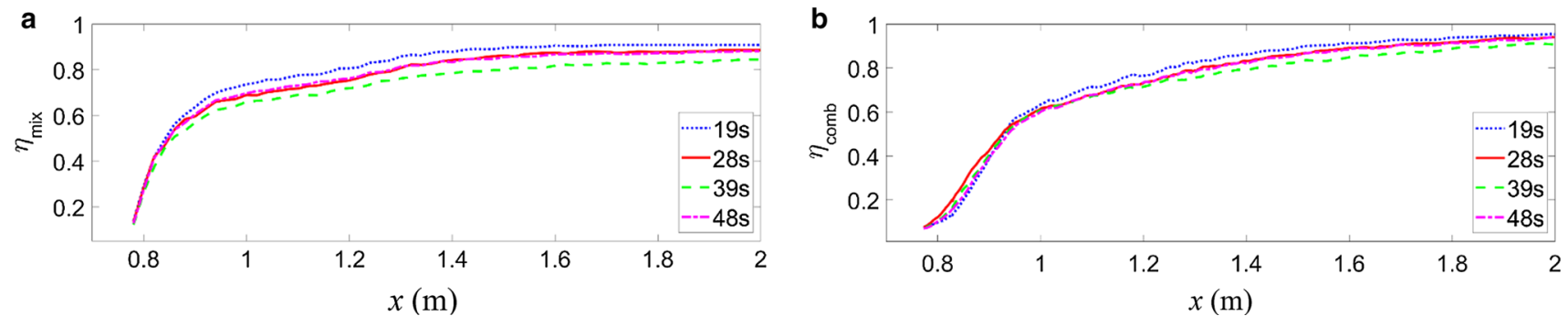

Fig. 8 a Mixing efficiency and $\mathbf{b}$ combustion efficiency predicted by different skeletal mechanisms for an elliptical combustor (reprinted with permission from Ref. [43])

speed. The 19s mechanism also predicts a slightly higher peak in the heat release rate.

As shown in Fig. 7, the discrepancies in the prediction of intermediate species are larger than those of the mean flow variables. The 39s mechanism underestimates the mass fraction of $\mathrm{OH}$ in the expander section, while the other predictions are similar. The predictions of $\mathrm{CO}$ converge in the rising stage but diverge beyond the peak location. The discrepancies among predictions by the different skeletal mechanisms are due to the significant changes in the reaction paths connected to the intermediate species. The reduction method eliminates the intermediate species and the reaction paths connected to them as much as possible, as long as the production rates of the final products are reasonably emulated. To better predict any specific intermediate species, the main reaction paths connected to them should be retained by including them as the target species.

As shown in Fig. 8, the mixing and combustion efficiencies predicted by the different skeletal kerosene mechanisms are similar, with the 19s mechanism slightly overestimating and the 39s mechanism slightly underestimating, with a maximum deviation of $5 \%$.

Historical statistics of Damköhler number $(D a)$ versus Re in Fig. 9 show that TCI relationship is significantly influ- enced by the chemical mechanisms. Fast-chemistry-assumed flamelet models are inapplicable to at least one-third of the data points, and the percentage is further increased for the 39s and 48 s predictions. As the reaction paths are simplified, the chemical timescales become shorter, and thus the flamelet mode increases for the $19 \mathrm{~s}$ and $28 \mathrm{~s}$ mechanisms. The ratios of the three combustion modes are almost the same for the 39s and $48 \mathrm{~s}$ mechanisms. Changes in the chemical mechanism influence not only the chemical timescale but also the species transport and turbulence characteristics when coupled with the flow.

\subsection{Influence of global equivalence ratio}

The peak pressure increases with the global equivalence ratio $(\Phi)$, whereas the influence of $\Phi$ on the wall heat flux seems to be non-monotonic and has no discernible rule. Figures 10-12 show the time-averaged wall pressure and wall heat flux at different global equivalence ratios from fuel-lean to fuel-rich conditions. The predicted pressure profiles agree well with the measurements, whether in the initial pressure rise or the peak value. The pressure rise ratio between the peak pressure and the initial pressure increases from 4 , to 4.5 to 5 as $\Phi$ increases from 0.6 , to 10 to 1.2 at an inlet $M a$ of 2 , and from 

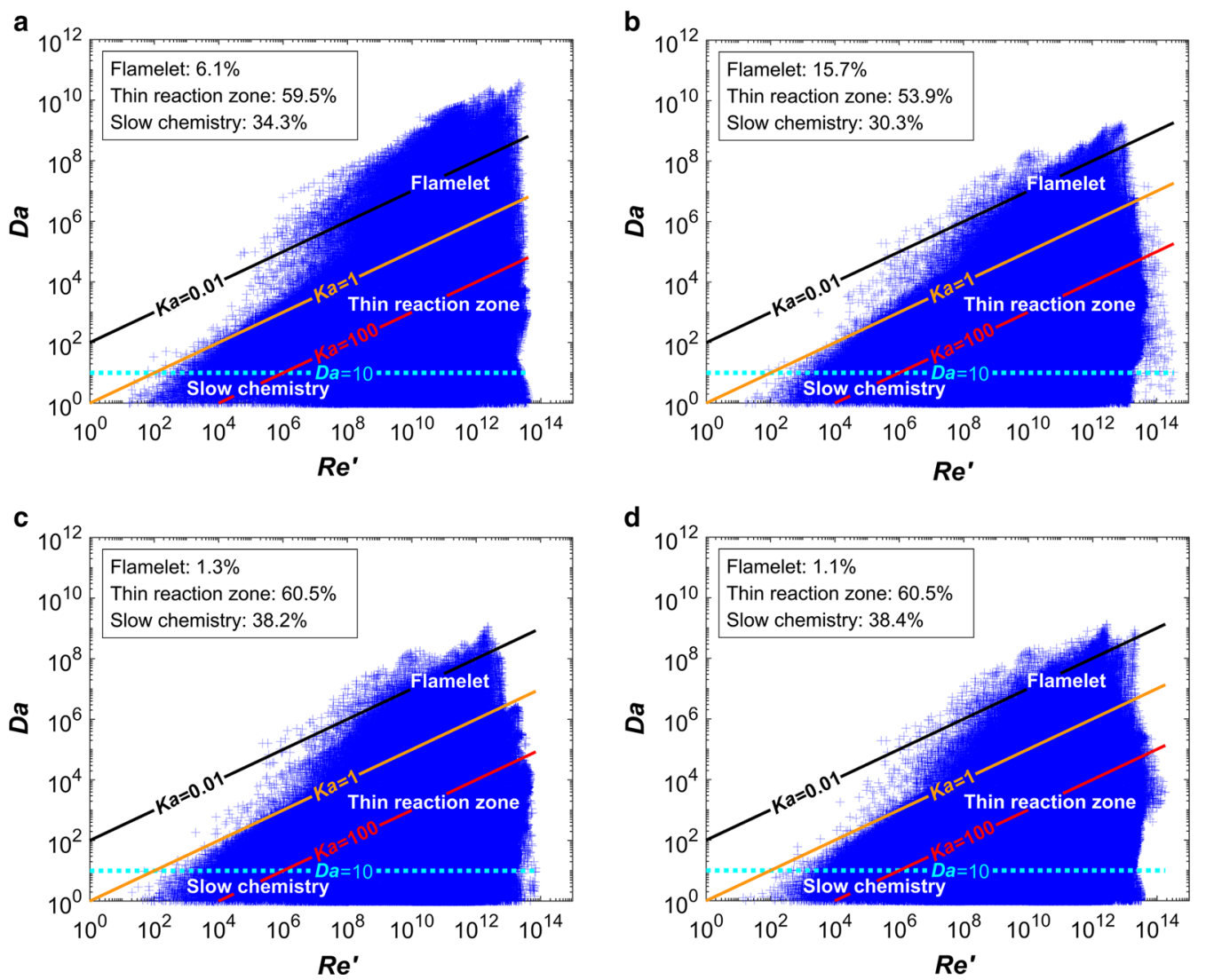

Fig. 9 Borghi diagrams predicted by a 19s, b 28s, c 39s, and d 48s mechanisms for an elliptical combustor (reprinted with permission from Ref. [43])

4 to 4.3 as $\Phi$ increases from 0.8 to 1 at an inlet $M a$ of 2.5 . Wall heat flux prediction is difficult both to measure and to predict, as it is influenced not only by the internal combustion but also by the wall heat transfer; thus it is usually even difficult to accurately predict its order of magnitude. In the results shown, the predicted wall heat flux is comparable to the measurements on different wall sides.

Figure 13 shows that as $\Phi$ increases, the stream-wise $M a$ becomes lower and the supersonic core shrinks considerably. This is as expected, since the heat addition becomes higher at $\Phi$ about 1.0, and heating always drives $M a$ toward 1 and thermal choking ( $\mathrm{d} M a / M a \sim \mathrm{d} T_{t} / T_{t}, T_{t}$ is total temperature). The instantaneous supersonic core delimited by the sonic lines is usually intermittent, although the mean supersonic core is continuous. A more general rule of thumb for judging the operation mode of a scramjet or ramjet is thus from the time-average supersonic flux ratio.

Figure 14 shows the main flow structures represented by the Laplacian of the density field $\nabla^{2} \rho$ for $\Phi=0.6,1.0$. The larger contrast confirms that the initial shock waves are stronger for $\Phi=0.6$, which could be related to the more symmetric boundary layer separation in the isolator under a lower $\Phi$. The fuel-rich mixing layer is more heavily corru- gated because the heat release becomes more intense as $\Phi$ increases. The main heat release regions are distributed primarily in the corrugated mixing layer above the cavity, and penetrate deeper into the supersonic core as $\Phi$ increases. For the upstream jet, the flame stabilizes in the jet wake to some extent at a higher $\Phi$ because the reactivity increases as the fuel become richer.

Plots of the heat release rate versus the mixture fraction space are shown for $\Phi=0.6,1.0$ in Fig. 15. The pyrolysis reactions in the oxygen-rich side are generally weak. The most violent pyrolysis reactions occur at a mixture fraction of $\xi=0.18$ for $\Phi=0.6$ and $\xi=0.25$ for $\Phi=1.0$. The pyrolysis region shifts toward the more fuel-rich side under the higher $\Phi$, because the higher jet penetration depth results in better contact with the high-temperature incoming flow. The Takeno flame index (TFI) [110] is used to denote the premixed and the non-premixed flame modes with positive and negative values, respectively, which are marked by two colors. The ratio of exothermic reactions under the premixed mode decreases from $40 \%$ to $26 \%$ as $\Phi$ increases, i.e., $40 \%$ at $\Phi=0.6$ and $26 \%$ at $\Phi=1.0$. The ratio of endothermic reactions under the premixed mode also decreases from $91 \%$ to $76 \%$ as $\Phi$ increases. Most of the endothermic reactions occur 

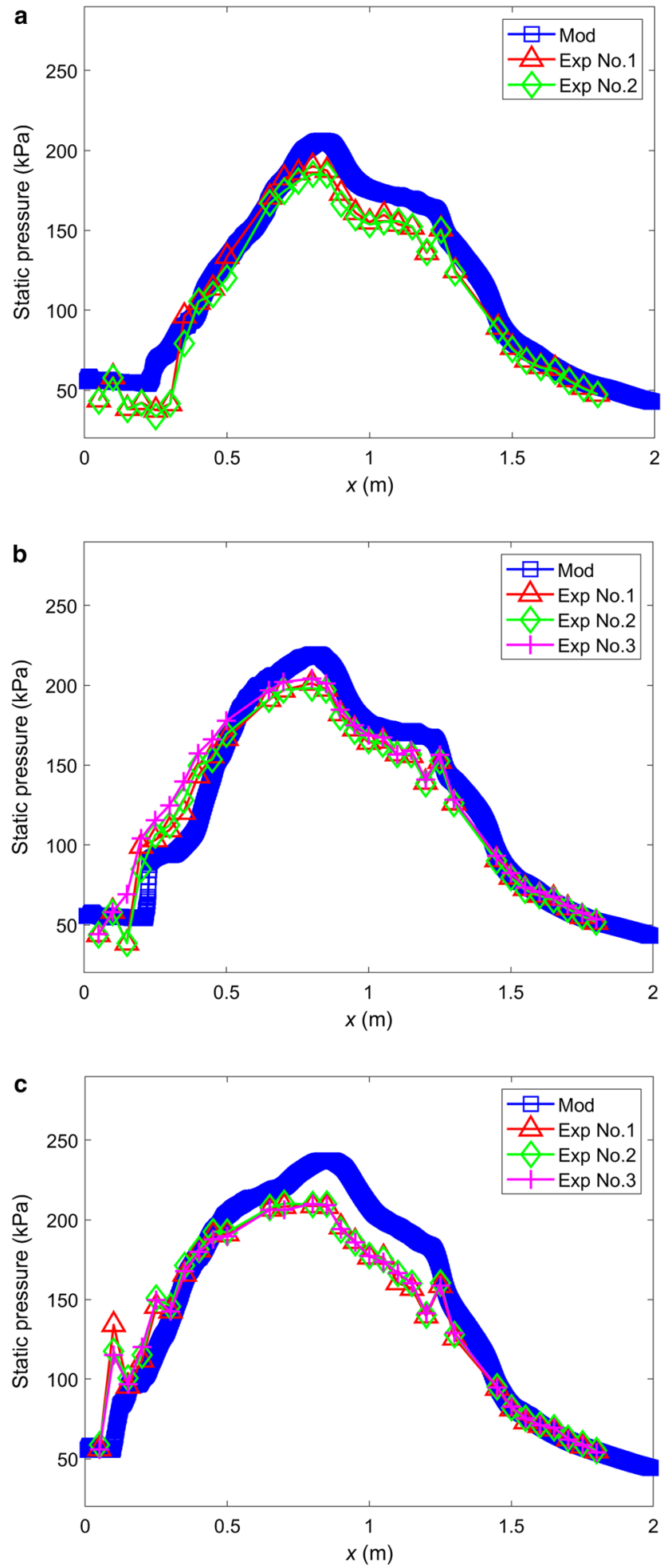

Fig. 10 Time-averaged wall pressure at $M a=2.0$ for a rectangular combustor with $\Phi$ is a $0.8, \mathbf{b} 1.0, \mathbf{c} 1.2$

under the premixed mode, and the ratio of the premixed mode decreases with the increase in $\Phi$. In addition to the primary peak slightly in the fuel-rich side, a secondary smaller peak

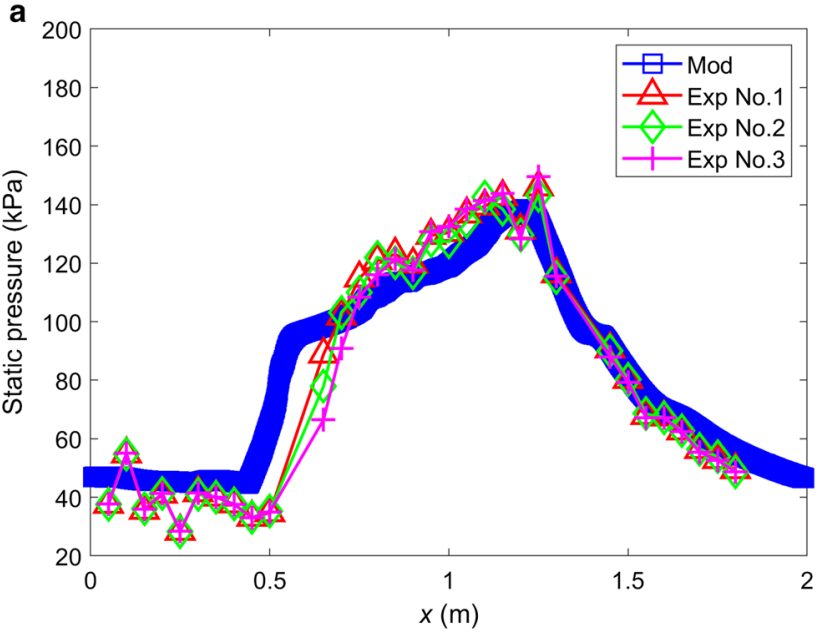

b

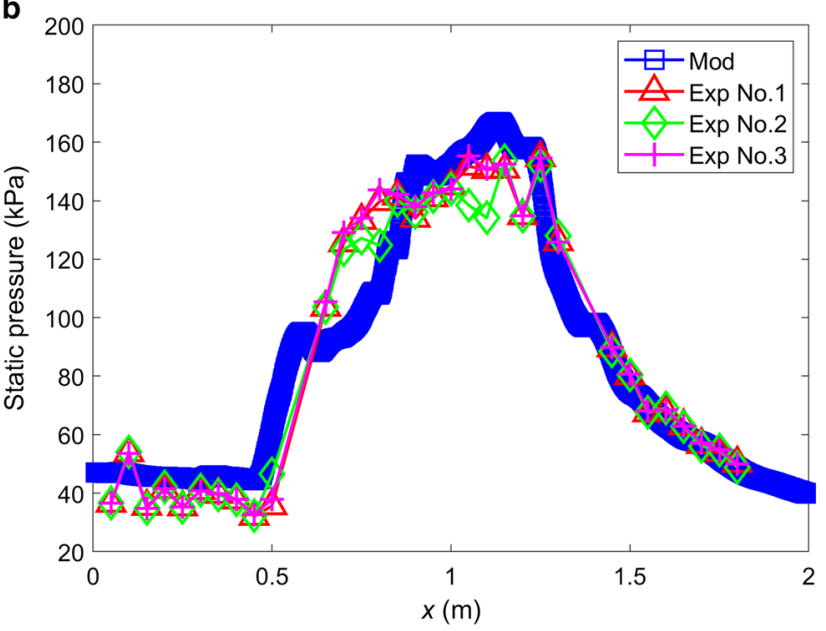

Fig. 11 Time-averaged wall pressure at $M a=2.5$ for a rectangular combustor with $\Phi$ is $\mathbf{a} 0.6$ and $\mathbf{b} 1.0$ (reprinted with permission from Ref. [46])

in the fuel-rich side, which corresponds to the initial oxidation chain reactions of small-molecule hydrocarbons, can be more clearly observed for the higher $\Phi$. The heat release rate indicates that both pyrolysis and oxidation reactions are intensified as $\Phi$ increases from 0.6 to 1.0 .

\subsection{Influence of inlet $M a$}

Figure 16 compares the measured and predicted wall pressure for inlet Mas of 2 and 3 for a round combustor. The initial pressure rise corresponds to the shock train, which shifts downstream as the inlet $M a$ increases. The shifting distance is roughly proportional to the displacement thickness of the boundary layer, which increases as $M a$ increases, and decreases as $R e$ increases. At a lower inlet $M a$ (e.g. 2.5), $R e$ also decreases, because of the same mass flow flux but higher static temperature. Thus the effects of $M a$ and $R e$ somewhat counteract one another. 

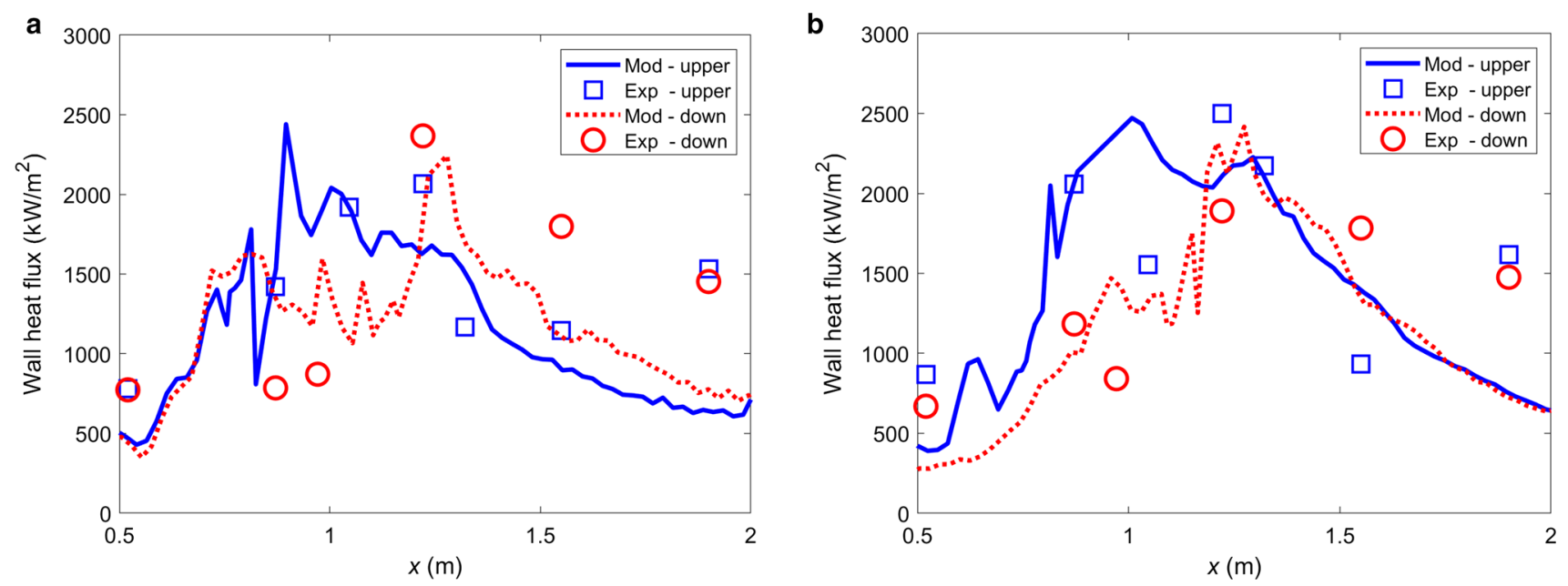

Fig. 12 Time-averaged wall heat flux at $M a=2.5$ for a rectangular combustor with $\Phi$ is $\mathbf{a} 0.6$ and $\mathbf{b} 1.0$ (reprinted with permission from Ref. [46])
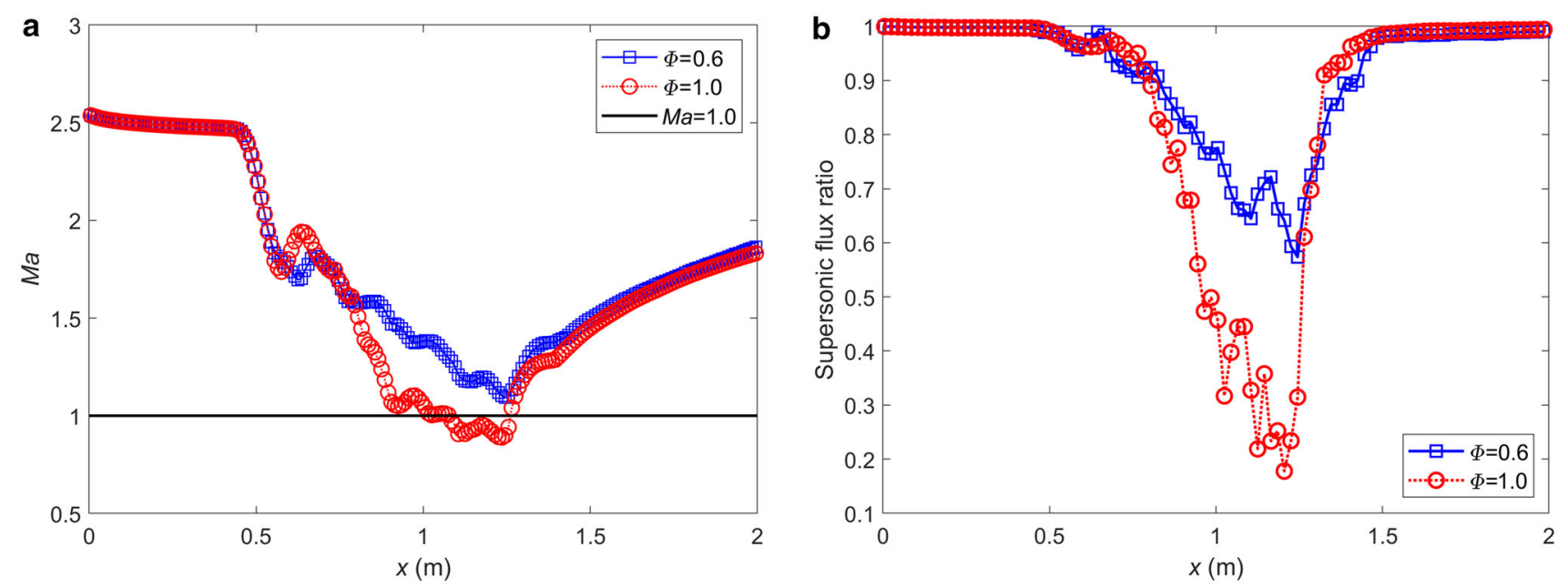

Fig. 13 Time-averaged $\mathbf{a} M a$ and $\mathbf{b}$ supersonic flux ratio for a rectangular combustor at $M a=2.5$ (reprinted with permission from Ref. [46])
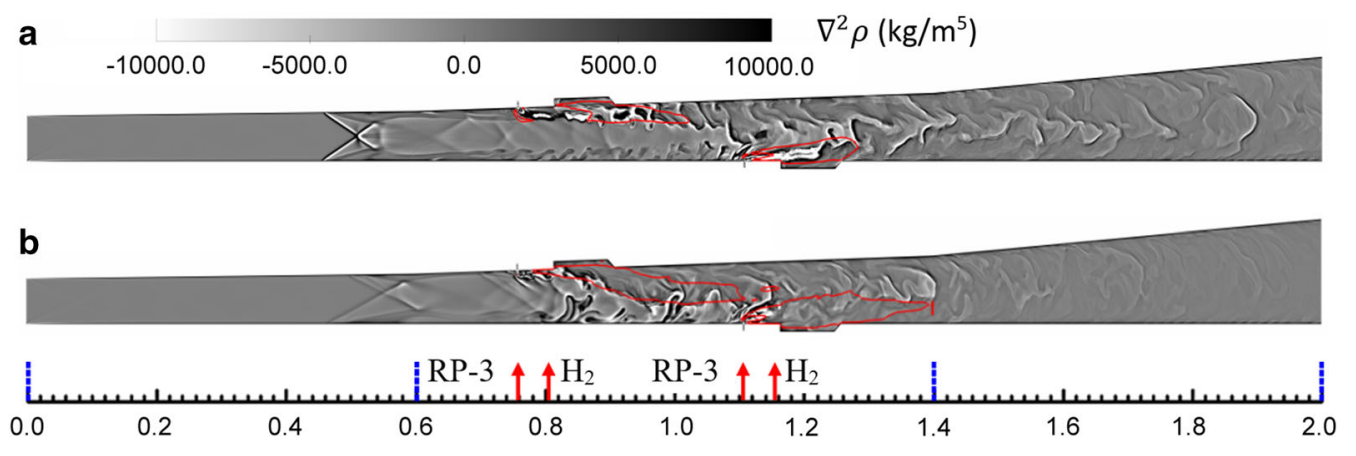

Fig. 14 Instantaneous synthetic shadowgraphs for a rectangular combustor with $\Phi$ is a 0.6 and b 1.0 with $\overline{\mathrm{d} Q}>0$ contours (reprinted with permission from Ref. [46])

Figures 17 and 18 show the instantaneous fields of $M a$ and static temperature at different inlet Mas. As Ma increases from 2.5 to 3 , the initial location of the shock train slides downstream for around $x=D_{\text {inlet }}\left(D_{\text {inlet }}\right.$ is the diameter of the isolator inlet). As the shock train moves downstream, the post-shock pressure and temperature both decrease, while the flow residence time shortens as the velocity near the fuel injectors increases; thus an increase in the inlet $M a$ should 

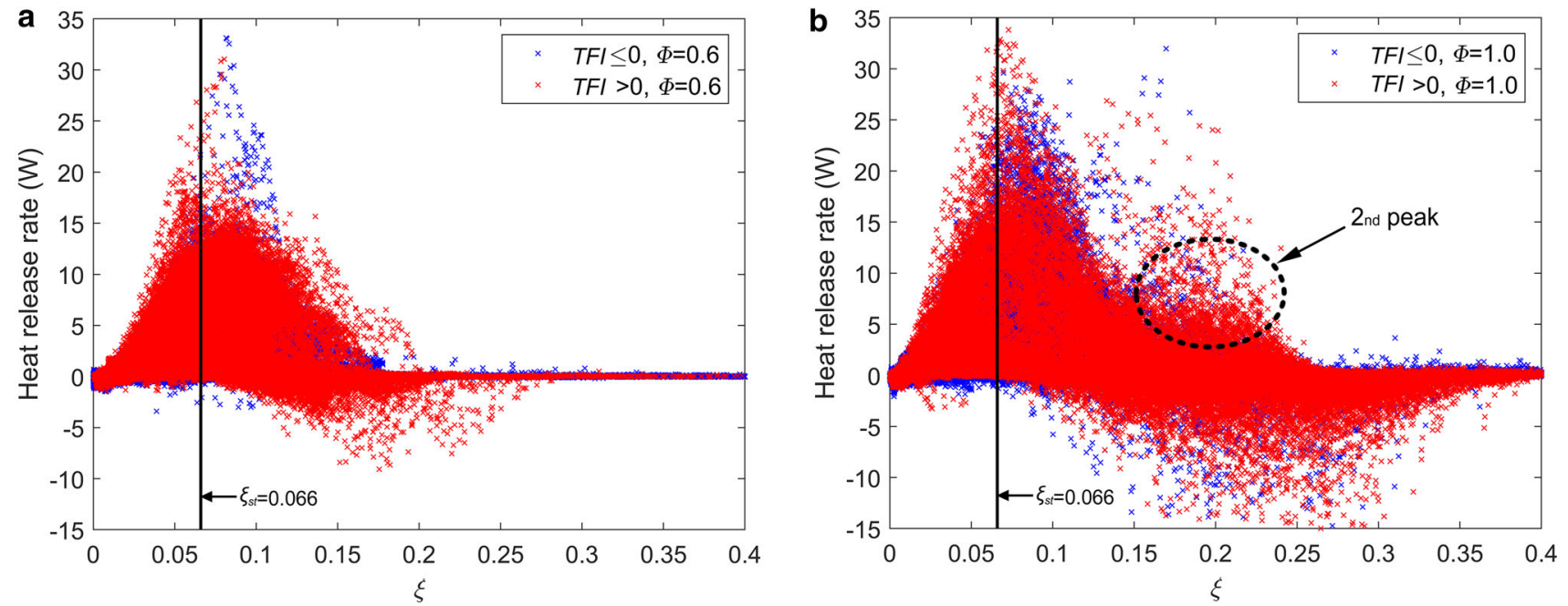

Fig. 15 Historical statistics of heat release rate versus mixture fraction for a rectangular combustor $\Phi$ is a 0.6 and b 1.0 (reprinted with permission from Ref. [46])
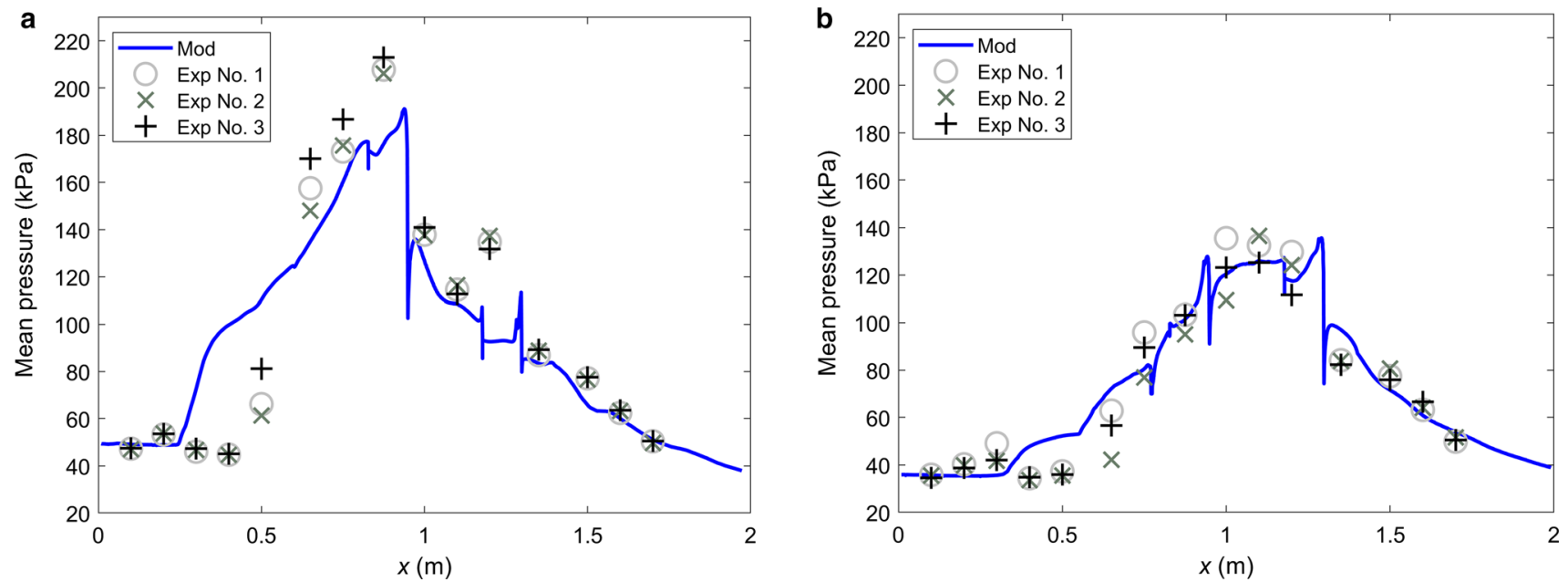

Fig. 16 Time-averaged wall pressure for a round combustor at $\mathbf{a} M a=2.5$ and $\mathbf{b} M a=3.0$ (reprinted with permission from Ref. [45])

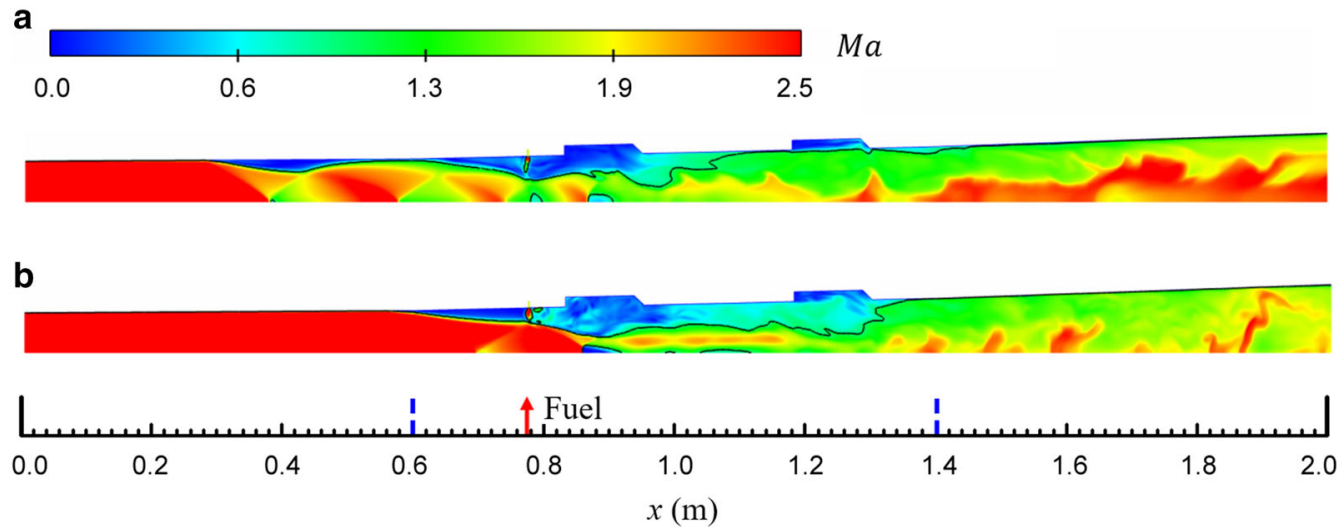

Fig. 17 Instantaneous fields of $M a$ for a round combustor at $\mathbf{a} M a=2.5$ and $\mathbf{b} M a=3.0$ (reprinted with permission from Ref. [45]) 

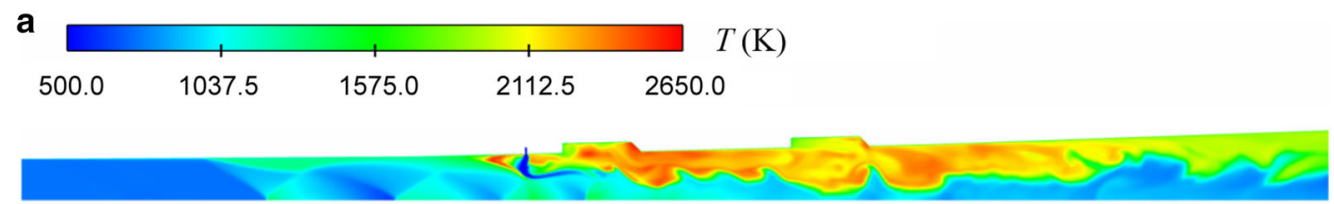

\section{b}

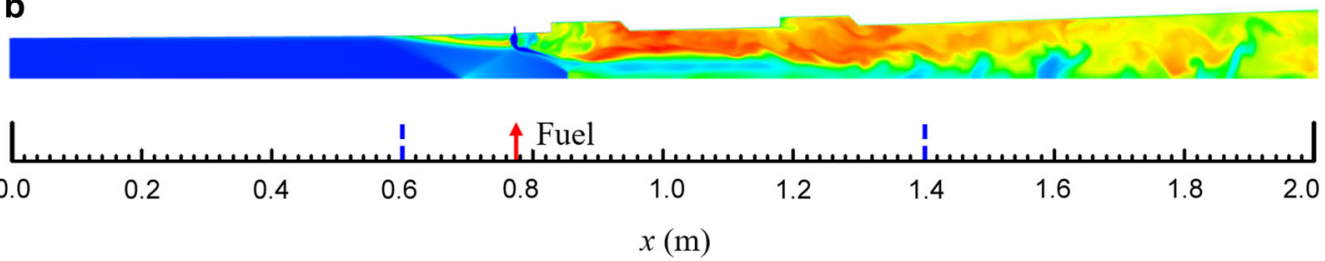

Fig. 18 Instantaneous fields of static temperature for a round combustor at $\mathbf{a} M a=2.5$ and $\mathbf{b} M a=3.0$ (reprinted with permission from Ref. [45])

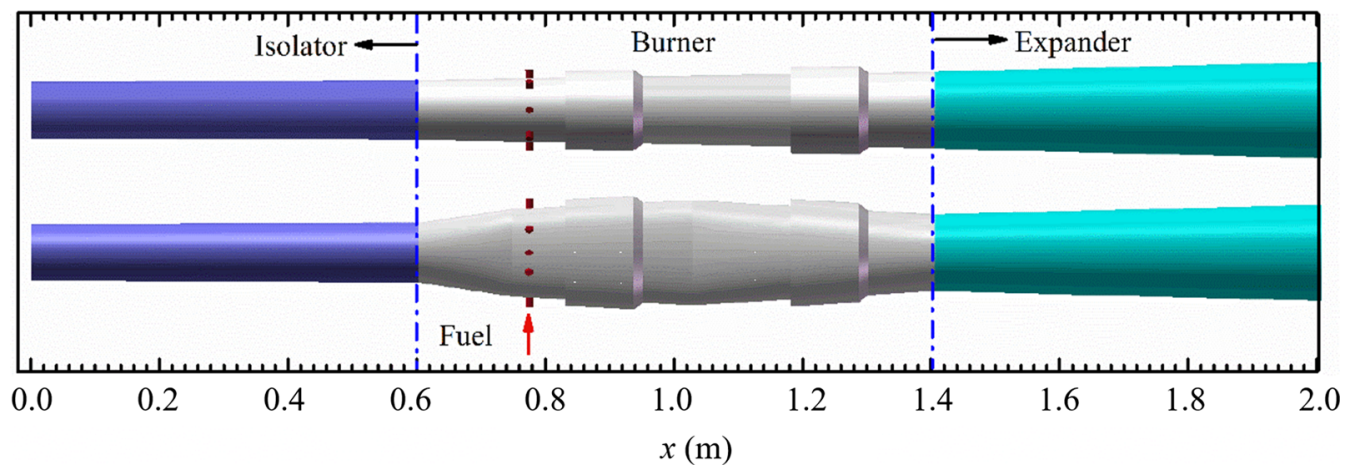

Fig. 19 Schematics of the (upper) round and (lower) RdEST supersonic combustors (reprinted with permission from Ref. [45])

reduce the reactivity and the pressure rise ratio. The same conclusion can be drawn based on Figs. $10 \mathrm{~b}$ and $11 \mathrm{~b}$ for the rectangular combustor.

\subsection{Non-rectangular supersonic combustors}

Non-rectangular supersonic combustors, such as round and elliptical combustors, can avoid the influence of corners on the internal flow, improve contact between the transverse fuel jets and the air cross-flow, and reduce structural strength and weight. Most current supersonic combustor studies are based on rectangular supersonic combustors, while very few studies have been reported on combustion characteristics in non-rectangular combustors. The earliest experimental tests on round and elliptical supersonic combustors were reported in the 1960s [111]. In recent years, round [112-115] and elliptical [116-119] supersonic combustors have attracted increasing attention.

A supersonic combustor was specifically designed with a changeable burner section connecting the same isolator and expander sections. Figure 19 schematically shows the round and the round-to-elliptical shape-transition (RdEST) scramjet combustors. The elliptical burner section was designed to have the same cross section area as the round one at the same stream-wise location.

As shown in Fig. 20, the RdEST combustor obviously has a higher pressure rise ratio than the round combustor. The final combustion efficiency is also higher for the RdEST combustor than the round one, as shown in Fig. 21. From the numerical shadowgraph in Fig. 22, it can be seen that as $M a$ increases, the shock train moves only slightly for the RdEST combustor, but it slides significantly downstream for the round combustor. The downstream mixing and combustion efficiencies are strongly influenced by the strength of the shock train; therefore, the RdEST combustor should have better combustion stability. The penetration depth of the fuel stream is confirmed to be lower, and the unburnt fuel stream spreads longer in the downstream for the RdEST combustor than the round combustor.

As shown in Fig. 23, the peculiarity of the elliptical combustor lies in the fact that the internal flow expands in the direction of the major axis, while it is compressed in the minor axis direction. Consequently, the three-dimensional shock waves in the shock train form elliptical cones. The supersonic core shrinks due to the heat addition as the flow enters the burner section and then expands again in the expander section. A much wider subsonic region exists in the dome formed 

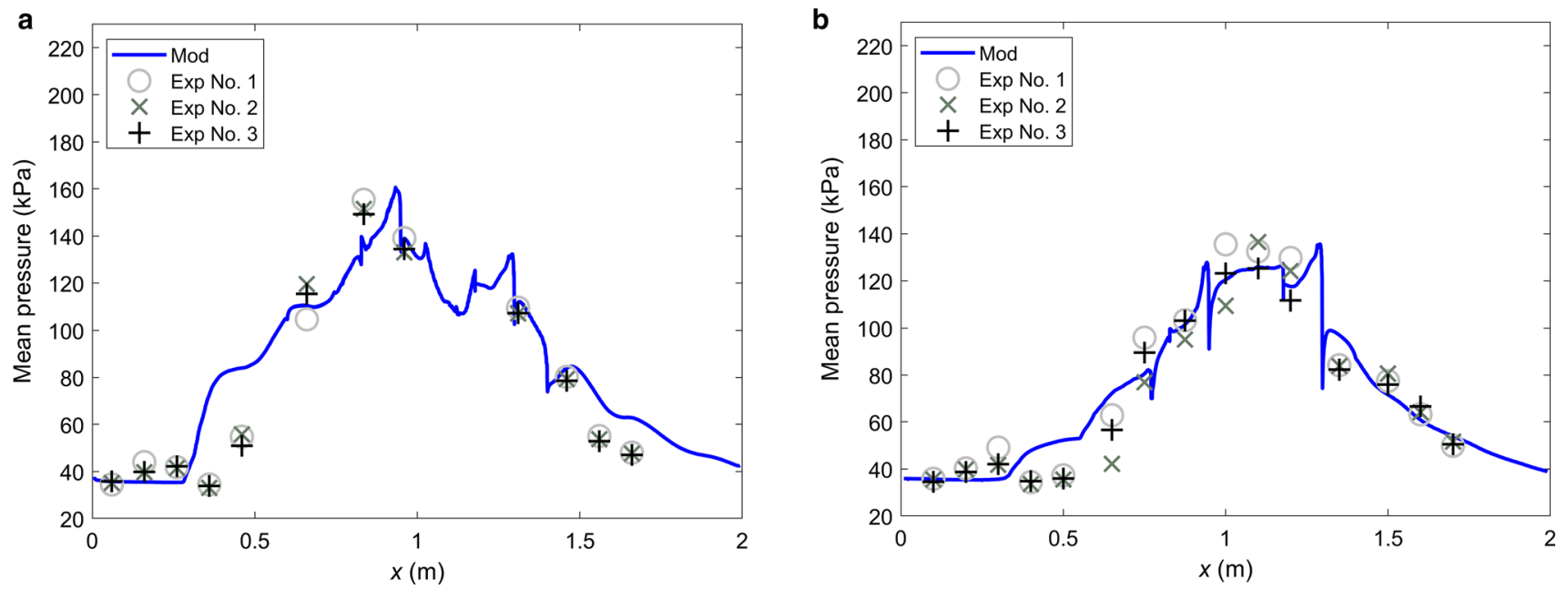

Fig. 20 Wall pressure for $\mathbf{a}$ RdEST combustor and $\mathbf{b}$ round combustor (reprinted with permission from Ref. [45])

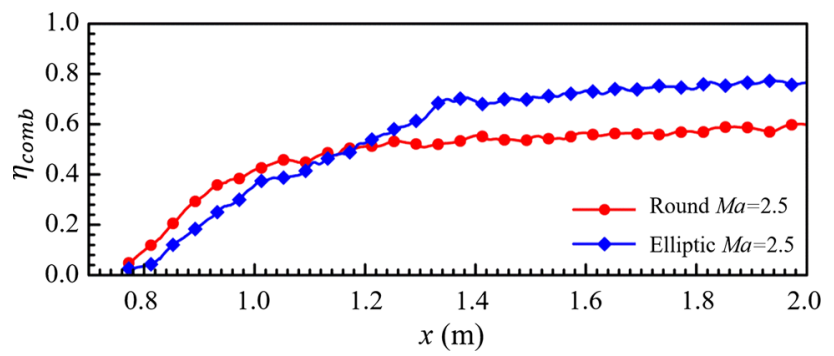

Fig. 21 Combustion efficiency for round and RdEST combustors (reprinted with permission from Ref. [45])

in the direction of the long axis, because the convex elliptical section indeed acts as a huge cavity to prolong the flow residence time. The shrinkage in the minor axis direction when transiting from round to elliptical cross section acts as a physical throat to anchor the shock train. The backward-facing step (backstep) region immediately following the round-ellipse transition point also induces rich large-scale vortexes to facilitate subsequent mixing.

The lack of discernible individual fuel streams based on the mixture fraction contours in Fig. 24 indicates that most of the fuel has mixed well with the vitiated air cross-flow behind the upstream cavity, and the temperature is favorable for combustion reactions. The reduced distance between the two opposite rows of the fuel jets in the direction of the short axis significantly increases the exchange of heat and highly reactive radicals across the symmetry planes, thus stabilizing the root of the flame in the upstream cavity. The subsonic regions in the "huge cavity" formed in the direction of the long axis also stabilize the flame by increasing the flow residence time and preheating the unburnt gas.

\subsection{Influence of domain symmetry}

Symmetry boundary treatment has been widely used in modeling symmetric and axisymmetric combustors, mainly to mitigate the huge computational cost, but few studies have been conducted to estimate the errors caused by this assumption. As the mean flow fields would remain symmetric, the symmetry assumption is generally acceptable for Reynoldsaveraged Navier-Stokes (RANS) modeling. However, it is questionable for LES modeling, because unsteady flows would not obey any kinds of symmetry restriction that would emerge only after the time averaging. For reacting flows, the influence of a split domain may be more noticeable, because even a small exchange of energy and radicals may significantly affect the reactivity on both sides. To the best of the author's knowledge, a first attempt to quantify the differences caused by this assumption was made by Yao et al. [64].

As shown in Fig. 25, the supersonic core shrinks as the heat addition is imposed. The location of the most shrunken supersonic core moves upstream in the full-domain modeling, suggesting that a more intense heat addition has occurred. The thickening of the boundary layer in the isolator section occurs more upstream in full-domain modeling because of the higher heat release and pressure rise ratio.

As expected, in Fig. 26, the instantaneous flow structures, especially the supersonic core and the boundary layer, are obviously asymmetric as indicated by the sonic lines. The flow becomes more asymmetric in the burner section as the combustion reactions take place. The upstream propagation of back pressure can also cause severe asymmetric boundary layer separation. The exchanges of energy and radicals during the asymmetric flow evolution will further exacerbate the flow asymmetry, as they alter the heat release rate on the two sides. 


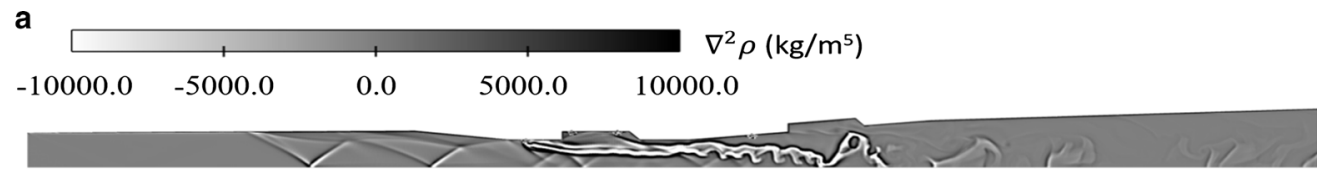

b

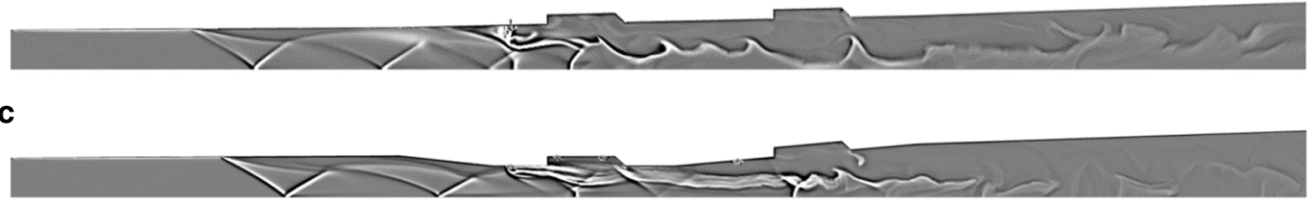

d

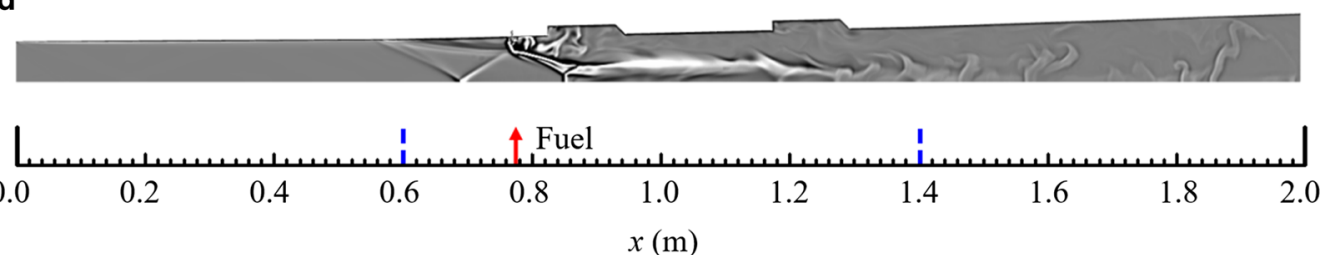

Fig. 22 Numerical shadowgraph for a elliptical combustor at $M a=2.5$, $\mathbf{b}$ round combustor at $M a=2.5$, $\mathbf{c}$ elliptical combustor at $M a=3.0, \mathbf{d}$ round combustor at $M a=3.0$ (reprinted with permission from Ref. [45])

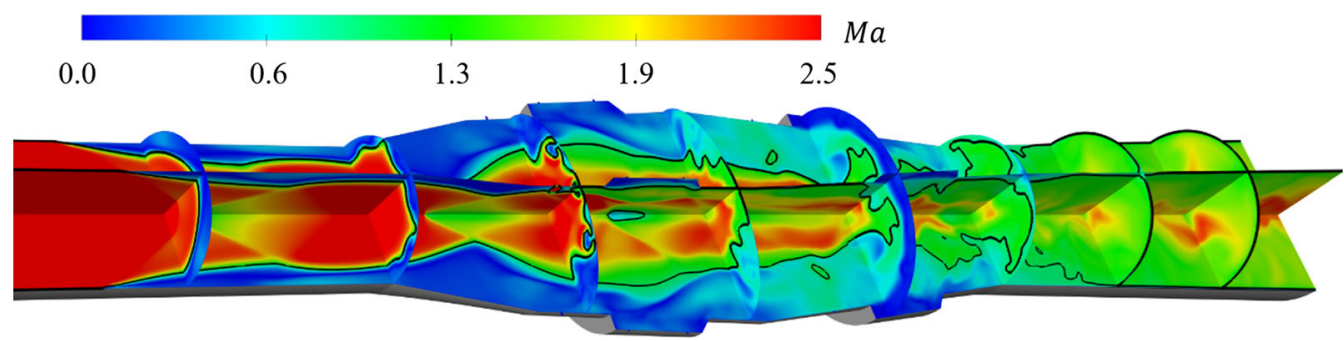

Fig. $23 \mathrm{Ma}$ with sonic lines for the RdEST combustor (reprinted with permission from Ref. [45])

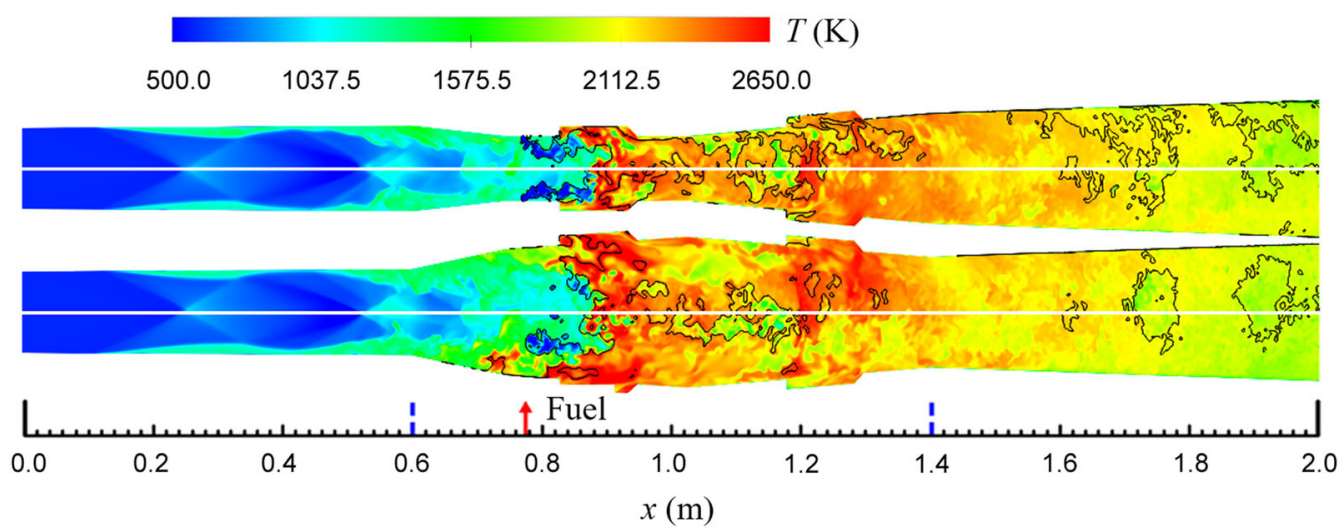

Fig. 24 Instantaneous temperature field with lines of stoichiometric mixture fraction $\left(\xi_{s t}=0.0686\right)$ for the RdEST combustor (reprinted with permission from Ref. [64])

From the statistics in Fig. 27, the key species for the combustion reactions based on path analysis, i.e., $\mathrm{C}_{2} \mathrm{H}_{3}$, $\mathrm{C}_{2} \mathrm{H}_{4}, \mathrm{CH}_{2} \mathrm{O}, \mathrm{HCO}$, and $\mathrm{CO}$, all have high imbalance, thus greatly enhancing the path fluxes by orders of magnitude, and a mutually aided ignition mechanism is hence established in the full-domain model, whereas autoignition occurs later in the quarter-domain model because it takes time for radical farming. In addition to the early ignition, the ongoing species exchanges further strengthen the downstream combustion reactions when the full domain is used. The fuel species $\left(\mathrm{NC}_{10} \mathrm{H}_{22}, \mathrm{IC}_{8} \mathrm{H}_{18}\right.$, and $\left.\mathrm{PCH}\right)$ flow in a reverse direction to all the other species across the minor symme- 


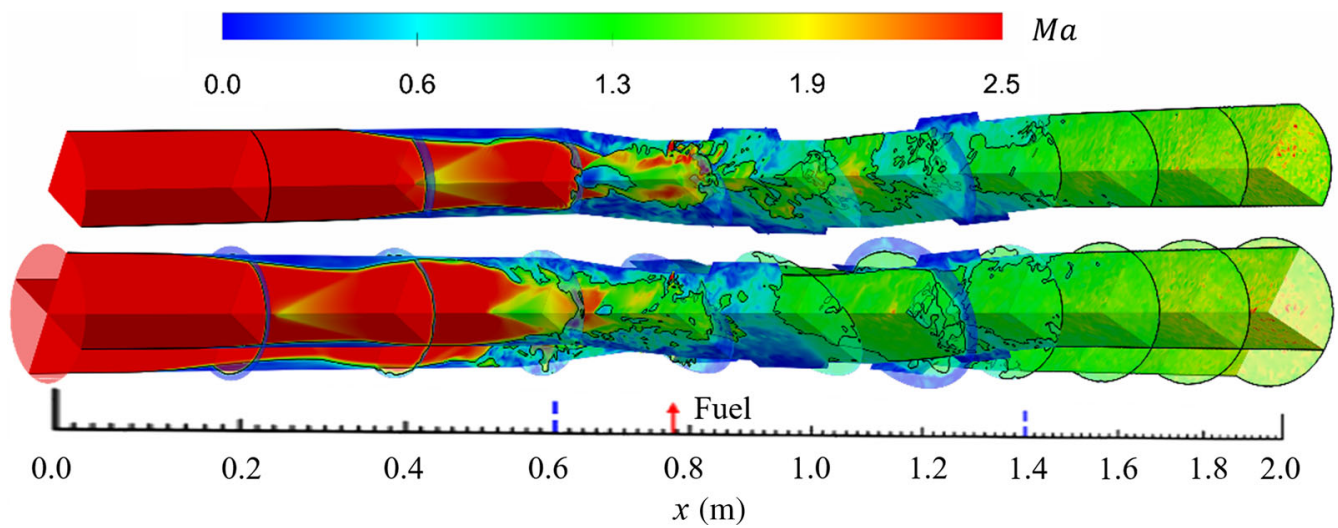

Fig. 25 Contours of instantaneous $M a$ with sonic lines for the RdEST combustor: quarter domain (upper), full domain (lower)

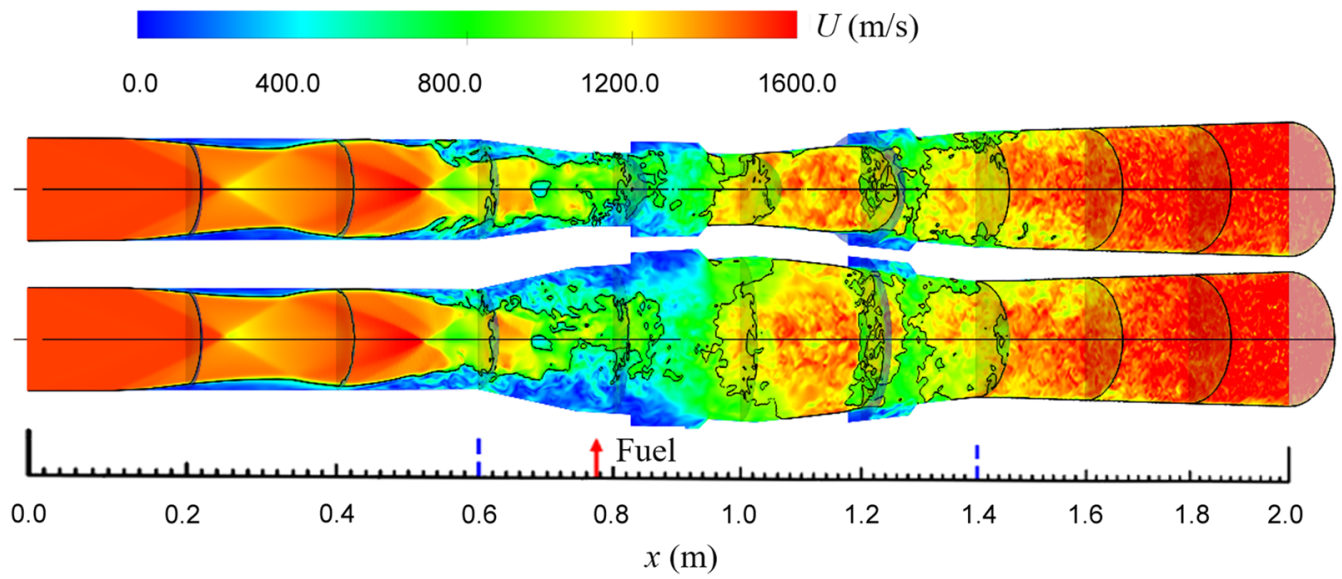

Fig. 26 Instantaneous velocity field with sonic lines for the RdEST combustor: minor plane (upper), major plane (lower) (reprinted with permission from Ref. [64])

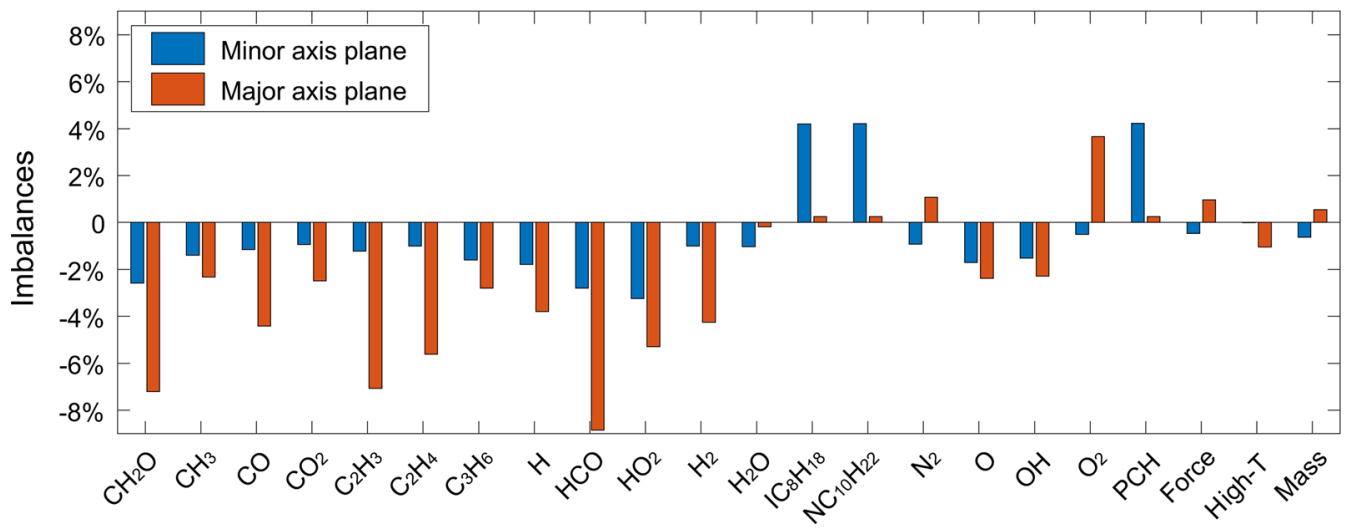

Fig. 27 Ensemble exchanges of mass, force, high-temperature gas, and species for the RdEST combustor (reprinted with permission from Ref. [64])

try planes, i.e., the fuel jets tilt slightly to one side, while the burnt mixture is then delivered back again. The small exchange imbalances in nitrogen, mass, high-temperature gas, and force indicate that the ensemble flow is statistically symmetric in mass, momentum, and energy, although the exchanges of individual species may be considerably nonconservative.
From the vortex structures in Fig. 28, the vortexes close to the symmetry planes are obviously influenced. For example, (1) counter-rotating vortexes (CRV) cannot be formed due to the lack of pairing, and the circumferential rollers cannot be fully developed into the $\Omega$-shaped vortexes; (2) the width of the quarter domain confines the size of large-scale transverse vortexes via truncation by the symmetry planes, and effective 

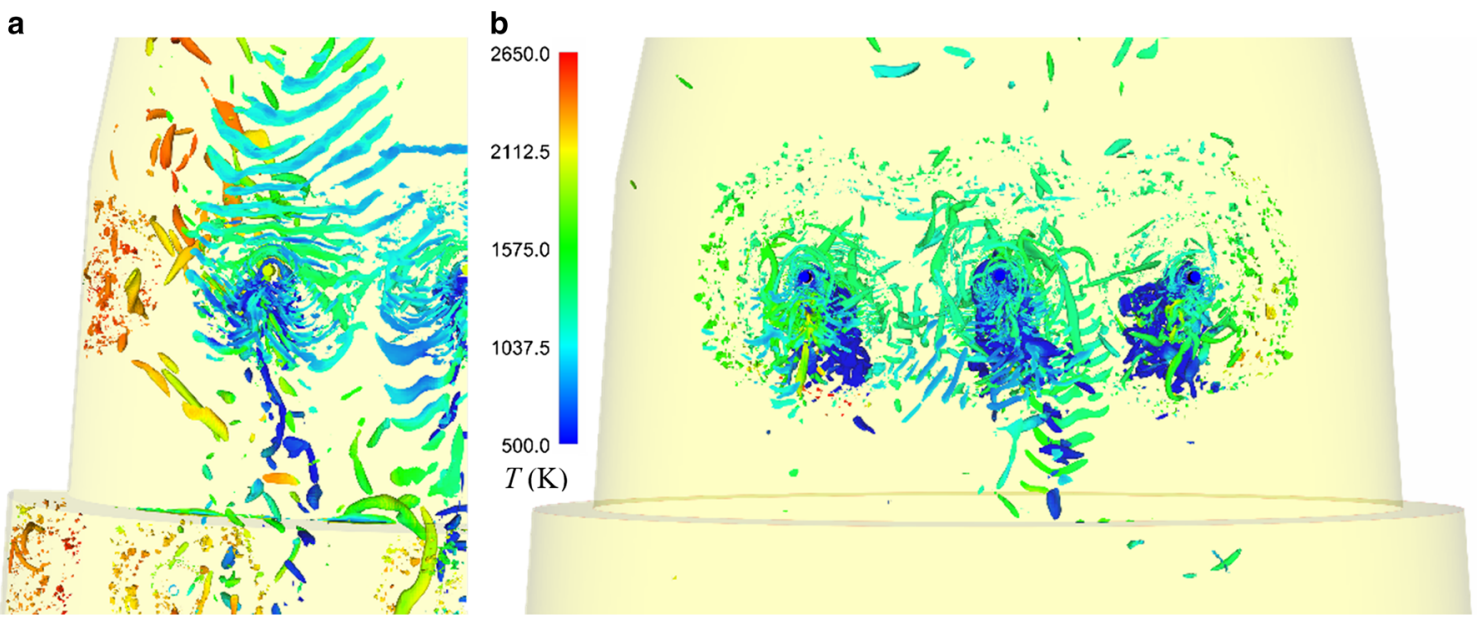

Fig. 28 Vortex structures represented by the iso-surfaces of Q-criterion (the second invariant of the velocity gradient tensor) at $2 \times 10^{10} \mathrm{~s}^{-2}$ and color-coded by temperature for the RdEST combustor, a quarter domain, b full domain (reprinted with permission from Ref. [64])
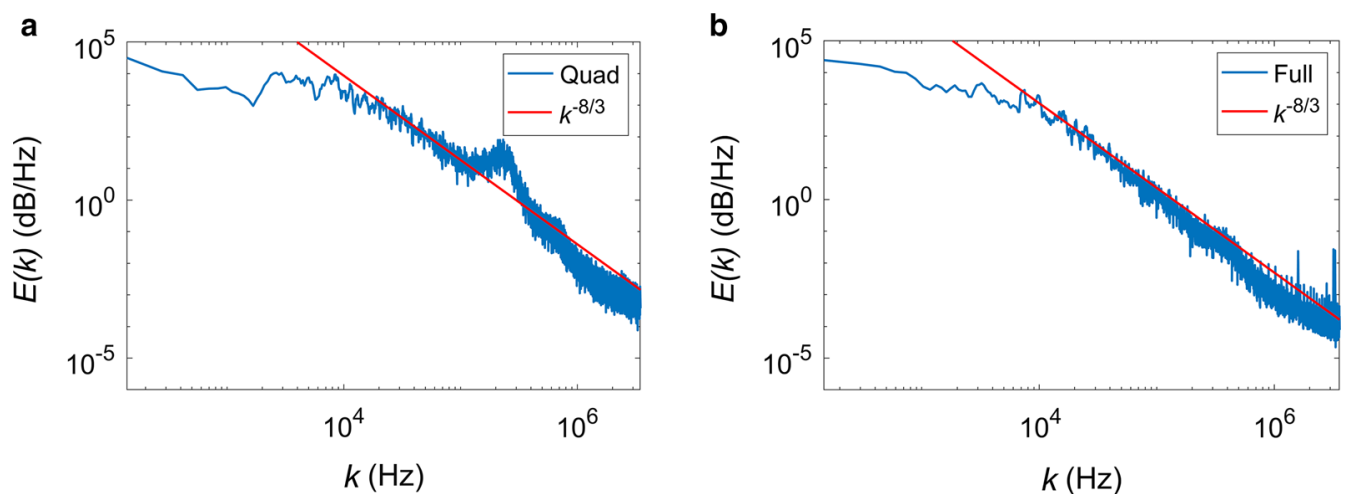

Fig. 29 Power spectral density diagrams for a quarter- and b full-domain models of the RdEST combustor (reprinted with permission from Ref. [64])

vortex stretching near the symmetry planes cannot take place. As a result, the vortex structures around the split injector are less rich, are smaller, and align mostly in the stream-wise direction compared with its complete counterpart in the full domain.

As shown in Fig. 29, the lateral motions normal to the symmetry planes in the quarter domain are restricted, and the local turbulence can no longer be well approximated as isotropic and homogeneous; consequently, a shorter inertial subrange is observed compared with the full-domain modeling. The decrease in integral-scale $R e$ in the quarter-domain modeling also contributes to the shorter inertial subrange. For both the quarter-domain and full-domain results, the dependence of energy density $E(k)$ at each frequency $k$ is fit to be $E(k)-k^{-8 / 3}$. In the quarter-domain modeling, a unique spike structure, which has been previously reported [120], exists to bridge the inertial subrange and the viscous dissipation subrange. The spectrum spike originates from the energy accumulation contributed by the backscatter energy from smaller scales and the forward scatter energy from the inertial subrange. The backscatter of kinetic energy into larger scales is rendered by the force imposed by the symmetry boundary conditions, which causes a strong anisotropic effect that enables one component of the sub-grid scale (SGS) stress to supersede the isotropizing restoration.

\section{Concluding remarks}

A brief review of the recent advances in kerosene-fueled supersonic combustion modeling is presented in this paper. The advantages and disadvantages of hydrogen and kerosene for the scramjet combustor are compared to show that kerosene is a more viable fuel option for the $M a$ range of 4-8, which is the main battlefield of short-term military applications. As the fuel of practical use for various propulsion systems, modeling studies of kerosene-fueled combustion are generally scarce in the published literature. The main challenges arise from the kinetic modeling of kerosene due to its complex composition and the involve- 
ment of thousands of elementary reactions. The timescales of the supersonic flow in a scramjet combustor and the combustion reactions of kerosene are both in the order of magnitude of $1 \mathrm{~ms}$, which implies that there is a complex turbulence-chemistry interaction, and most importantly, fast-chemistry-assumed combustion models, e.g., flamelet models, are inapplicable for kerosene combustion modeling. This implies a huge computation cost, as finite-rate combustion models are usually required for kerosene combustion models. Therefore, as the first priority, detailed kinetic mechanisms for kerosene must be significantly reduced for modeling use. The detailed mechanisms based on various surrogates for different kerosene types are reviewed, and global and reduced/skeletal mechanisms available in the literature are then thoroughly summarized. As of this writing, the smallest skeletal kerosene mechanism has only 19 species and 53 reversible reactions. The first attempt to model supersonic combustion based on a realistic skeletal kerosene mechanism shows remarkable improvement in modeling fidelity, as many more flow details are captured. Therefore, the modeling history of kerosene-fueled supersonic combustion can be roughly divided into two stages: (1) studies based on global chemistry, mostly before 2010 and (2) those based on reduced/skeletal chemistry after 2014. In addition to the improvement in kinetic modeling, second-stage models also demonstrate significant improvements in mesh resolution and numerical methods. It is expected that with the advances in computational technology, more detailed mechanisms will be applied to further increase kinetic accuracy as well as model fidelity.

Here, the most recent advances in kerosene-fueled supersonic combustion modeling, based mostly on skeletal mechanisms, were briefly introduced. The influences of kinetic mechanisms, global equivalence ratios, inlet $M a$, geometric shape, and domain symmetry were analyzed based on high-fidelity modeling and available measurements. Measurements in supersonic combustion, whether ground- or flight-based, are difficult and high-cost; thus little insight has been provided for the transient internal flow and thermal environments in supersonic combustors. Unlike subsonic flows, high-fidelity modeling with accurate descriptions of both flow and chemistry is considered not merely supplementary, but is indispensable for gaining an in-depth understanding of the internal flow, mixing, and combustion processes inside the combustors, and for the development of new supersonic combustors.

Acknowledgements This research is supported by the Training Program of the Major Research Plan of the National Natural Science Foundation of China (Grant 91641110), the National Natural Science Foundation of China (Grant 11502270), and the State Key Laboratory of High Temperature Gas Dynamics Innovative Foundation (Grant LHD2018JS01). The authors are grateful to the National Supercomputer Center in Tianjin for providing the computational resource.
Availability of supporting data Permission for reprinting of the cited figures from the copyright holders: American Institute of Aeronautics and Astronautics (AIAA) and American Chemical Society (ACS).

\section{References}

1. Curran, E.T., Murthy, S.N.B.: High-Speed Flight Propulsion Systems. American Institute of Aeronautics and Astronautics, Washington, DC (1991)

2. Maurice, L., Edward, T., Griffiths, J.: Liquid hydrocarbon fuels for hypersonic propulsion. Scramjet propulsion 189, 757-822 (2001)

3. Hui, X., Sung, C.J.: Laminar flame speeds of transportationrelevant hydrocarbons and jet fuels at elevated temperatures and pressures. Fuel 109, 191-200 (2013)

4. Dagaut, P., Cathonnet, M.: The ignition, oxidation, and combustion of kerosene: a review of experimental and kinetic modeling. Prog. Energy Combust. Sci. 32, 48-92 (2006)

5. Vasu, S.S., Davidson, D.F., Hanson, R.K.: Jet fuel ignition delay times: shock tube experiments over wide conditions and surrogate model predictions. Combust. Flame 152, 125-143 (2008)

6. Fiorina, B., Vié, A., Franzelli, B., et al.: Modeling challenges in computing aeronautical combustion chamber. Aerospacelab J. 11, 1-19 (2016)

7. Yan, Y., Liu, Y., Di, D., et al.: Simplified chemical reaction mechanism for surrogate fuel of aviation kerosene and its verification. Energy Fuels 30, 10847-10857 (2016)

8. Kundu, K.P., Deur, J.M.: A simplified reaction mechanism for calculation of emissions in hydrocarbon (jet-a) combustion. In: AIAA/SAE/ASME/ASEE 29th joint propulsion conference and exhibit. Monterey, CA, 28-30 June (1993)

9. Gueret, C., Cathonnet, M., Boettner, J.C., et al.: Experimental study and modeling of kerosene oxidation in a jet-stirred flow reactor. Symposium (International) on Combustion 23, 211-216 (1991)

10. Schulz, W.D.: Oxidation products of a surrogate JP-8 fuel. ACS Petrol. Chem. Div. Preprints 37, 383-392 (1991)

11. Heneghan, S.P., Locklear, S.L., Geiger, D.L.I., et al.: Static tests of jet fuel thermal and oxidative stability. J. Propul. Power 9, 5-9 (1993)

12. Violi, A., Yan, S., Eddings, E.G., et al.: Experimental formulation and kinetic model for JP-8 surrogate mixtures. Combust. Sci. Technol. 174, 399-417 (2002)

13. Cooke, J.A., Bellucci, M., Smooke, M.D., et al.: Computational and experimental study of JP-8, a surrogate, and its components in counterflow diffusion flames. Proc. Combust. Inst. 30, 439-446 (2005)

14. Agosta, A.: Development of a chemical surrogate for JP-8 aviation fuel using a pressurized flow reactor. [Master Thesis], Drexel University (2002)

15. Humer, S., Frassoldati, A., Granata, S., et al.: Experimental and kinetic modeling study of combustion of JP-8, its surrogates and reference components in laminar nonpremixed flows. Proc. Combust. Inst. 31, 393-400 (2007)

16. Daniau, E., Bouchez, M., Bounaceur, R., et al.: Contribution to scramjet active cooling analysis using $n$-dodecane decomposition model as a generic endothermic fuel. In: 12th AIAA international space planes and hypersonic systems and technologies. Norfolk, Virginia, 15-19 December (2003)

17. Dagaut, P., El Bakali, A., Ristori, A.: The combustion of kerosene: experimental results and kinetic modelling using 1- to 3-component surrogate model fuels. Fuel 85, 944-956 (2006)

18. Colket, M., Edwards, T., Williams, S., et al.: Development of an experimental database and kinetic models for surrogate jet fuels. 
In: 45th AIAA aerospace sciences meeting and exhibit. Reno, Nevada, 8-11 January (2007)

19. Honnet, S., Seshadri, K., Niemann, U., et al.: A surrogate fuel for kerosene. Proc. Combust. Inst. 32, 485-492 (2009)

20. Lindstedt, R.P., Maurice, L.Q.: Detailed chemical-kinetic model for aviation fuels. J. Propul. Power 16, 187-195 (2000)

21. Dooley, S., Won, S.H., Chaos, M., et al.: A jet fuel surrogate formulated by real fuel properties. Combust. Flame 157, 2333-2339 (2010)

22. Dooley, S., Won, S.H., Heyne, J., et al.: The experimental evaluation of a methodology for surrogate fuel formulation to emulate gas phase combustion kinetic phenomena. Combust. Flame 159, 1444-1466 (2012)

23. Moss, J.B., Aksit, I.M.: Modelling soot formation in a laminar diffusion flame burning a surrogate kerosene fuel. Proc. Combust. Inst. 31, 3139-3146 (2007)

24. Naik, C.V., Puduppakkam, K.V., Modak, A., et al.: Detailed chemical kinetic mechanism for surrogates of alternative jet fuels. Combust. Flame 158, 434-445 (2011)

25. Mzé-Ahmed, A., Dagaut, P., Hadj-Ali, K., et al.: Oxidation of a coal-to-liquid synthetic jet fuel: experimental and chemical kinetic modeling study. Energy Fuels 26, 6070-6079 (2012)

26. Dagaut, P., Karsenty, F., Dayma, G., et al.: Experimental and detailed kinetic model for the oxidation of a gas to liquid (gtl) jet fuel. Combust. Flame 161, 835-847 (2014)

27. Dagaut, P., Dayma, G., Karsenty, F., et al.: The combustion of synthetic jet fuels (gas to liquid and coal to liquid) and multicomponent surrogates: Experimental and modeling study. In: Proceedings of ASME Turbo Expo 2015: Turbine Technical Conference and Exposition. Montréal, Canada, 15-19 June (2015)

28. Fan, X., Yu, G.: Analysis of thermophysical properties of Daqing RP-3 aviation kerosene. J. Propul. Technol. 27, 187-192 (2006)

29. Zheng, D., Yu, W., Zhong, B.: RP-3 aviation kerosene surrogate fuel and the chemical reaction kinetic model. Acta Phys. Chim. Sin. 31, 636-642 (2015)

30. Dagaut, P., Reuillon, M., Boettner, J.C., et al.: Kerosene combustion at pressures up to $40 \mathrm{~atm}$ : Experimental study and detailed chemical kinetic modeling. Symposium (International) on Combustion 25, 919-926 (1994)

31. Dagaut, P.: On the kinetics of hydrocarbons oxidation from natural gas to kerosene and diesel fuel. Phys. Chem. Chem. Phys. 4, 2079-2094 (2002)

32. Lu, T., Law, C.K.: Toward accommodating realistic fuel chemistry in large-scale computations. Prog. Energy Combust. Sci. 35, 192-215 (2009)

33. Hautman, D.J., Dryer, F.L., Schug, K.P., et al.: A multiple-step overall kinetic mechanism for the oxidation of hydrocarbons. Combust. Sci. Technol. 25, 219-235 (1981)

34. Najjar, Y.S.H., Goodger, E.M.: Soot oxidation in gas turbines using heavy fuels. 2. Fuel. 60, 987-990 (1981)

35. Najjar, Y.S.H., Goodger, E.M.: Soot formation in gas turbines using heavy fuels. 1. Fuel. 60, 980-986 (1981)

36. Westbrook, C.K., Dryer, F.L.: Chemical kinetic modeling of hydrocarbon combustion. Prog. Energy Combust. Sci. 10, 1-57 (1984)

37. Aly, S.L., Salem, H.: Prediction of premixed laminar flame characteristics of commercial kerosene fuel. Fuel 68, 1203-1209 (1989)

38. Gueret, C., Cathonnet, M., Boettner, J.C., et al.: Experimental study and modeling of kerosene oxidation in a jet-stirred flow reactor. Symposium (International) on Combustion 23, 211-216 (1990)

39. Wang, T.S.: Thermophysics characterization of kerosene combustion. J. Thermophys. Heat Transfer 15, 140-147 (2001)

40. Franzelli, B., Riber, E., Sanjosé, M., et al.: A two-step chemical scheme for kerosene-air premixed flames. Combust. Flame 157, 1364-1373 (2010)
41. Choi, J.Y.: A quasi global mechanism of kerosene combustion for propulsion applications. In: 47th AIAA/ASME/SAE/ASEE joint propulsion conference and exhibit. San Diego, California, 31 July-3 August (2011)

42. Hou, L.Y., Niu, D.S., Pan, P.F., et al.: Effects of kerosene global reaction mechanisms on supersonic combustion. J. Propul. Technol. 34, 938-943 (2013)

43. Yao, W., Wu, K., Fan, X.: Development of skeletal kerosene mechanisms and application to supersonic combustion. Energy Fuels 32, 12992-13003 (2018)

44. Yao, W., Wang, J., Lu, Y., et al.: Skeletal mechanism generation based on DRGEPSA for Daqing RP-3 aviation kerosene and numerical validation. In: the 7th Chinese National Conference on Hypersonic Science and Technology, Beijing, 29-31 October (2014)

45. Yao, W., Yuan, Y., Li, X., et al.: Comparative study of elliptic and round scramjet combustors fueled by RP-3. J. Propul. Power 34, 772-786 (2018)

46. Yao, W., Lu, Y., Wu, K., et al.: Modeling analysis of an activelycooled scramjet combustor under different kerosene/air ratios. J. Propul. Power 34, 975-991 (2018)

47. Yao, W., Yuan, Y., Li, X., et al.: A comparative study of elliptic and round scramjet combustors by improved delayed detached eddy simulation. In: 21st AIAA International Space Planes and Hypersonics Technologies Conference. Xiamen, China, 6-9 March (2017)

48. Yao, W., Lu, Y., Li, X., et al.: Improved delayed detached eddy simulation of a high-ma active-cooled scramjet combustor based on skeletal kerosene mechanism. In: 52nd AIAA/SAE/ASEE Joint Propulsion Conference. Salt Lake City, Utah, 25-27 July (2016)

49. Yao, W., Wang, J., Lu, Y., et al.: Full-scale detached eddy simulation of kerosene fueled scramjet combustor based on skeletal mechanism. In: 20th AIAA International Space Planes and Hypersonic Systems and Technologies Conference. Glasgow, Scotland, 6-9 July (2015)

50. Liu, B., He, G.Q., Qin, F., et al.: Simulation of kerosene fueled RBCC engine based on skeletal mechanism. In: 21st AIAA International Space Planes and Hypersonics Technologies Conference, Xiamen, China, 6-9 March (2017)

51. Liu, Y., Liu, Y., Chen, D., et al.: A simplified mechanistic model of three-component surrogate fuels for RP-3 aviation kerosene. Energy Fuels 32, 9949-9960 (2018)

52. Zeng, W., Liang, S., Li, H.-X., et al.: Chemical kinetic simulation of kerosene combustion in an individual flame tube. J. Adv. Res. 5, 357-366 (2014)

53. Zeng, W., Liu, J.C., Chen, X.X., et al.: A new reduced reaction mechanism of a surrogate fuel for kerosene. Can. J. Chem. Eng. 91, 483-489 (2013)

54. Huang, W., Chen, F., Liu, H., et al.: Modeling chemical mechanism for surrogate jet fuel under scramjet operating conditions. In: 54th AIAA Aerospace Sciences Meeting. San Diego, California, 4-8 January (2016)

55. Xu, J., Guo, J., Liu, A., et al.: Construction of autoignition mechanisms for the combustion of RP-3 surrogate fuel and kinetics simulation. Acta Phys. Chim. Sin. 31, 643-652 (2015)

56. Zettervall, N., Fureby, C., Nilsson, E.J.K.: A small skeletal kinetic mechanism for kerosene combustion. Energy Fuels 30, 9801-9813 (2016)

57. Strelkova, M.I., Kirillov, I.A., Potapkin, B.V., et al.: Detailed and reduced mechanisms of jet-a combustion at high temperatures. Combust. Sci. Technol. 180, 1788-1802 (2008)

58. Slavinskaya, N.A.: Skeletal mechanism for kerosene combustion with pah production. In: 46th AIAA Aerospace Sciences Meeting and Exhibit. Reno, Nevada, 7-10 January (2008) 
59. Koniavitis, P., Rigopoulos, S., Jones, W.P.: Reduction of a detailed chemical mechanism for a kerosene surrogate via RCCE-CSP. Combust. Flame 194, 85-106 (2018)

60. Yao, W., Wu, K., Lee, Y., et al.: Influence of chemical mechanisms on supersonic combustion characteristics fueled by kerosene. In: 2018 Joint Propulsion Conference, AIAA Propulsion and Energy Forum and Exposition. Cincinnati, Ohio, 9-11 July (2018)

61. Davidson, D.F., Shao, J., Parise, T., et al.: Shock tube measurements of jet and rocket fuel ignition delay times. In: 55th AIAA Aerospace Sciences Meeting. Grapevine, Texas, 9-13 January (2017)

62. Niemeyer, K.E., Sung, C.J., Raju, M.P.: Skeletal mechanism generation for surrogate fuels using directed relation graph with error propagation and sensitivity analysis. Combust. Flame 157, 1760-1770 (2010)

63. Wu, K., Yao, W., Fan, X.: Development and fidelity evaluation of a skeletal ethylene mechanism under scramjet-relevant conditions. Energy Fuels 31, 14296-14305 (2017)

64. Yao, W., Wu, K., Fan, X.: Influences of domain symmetry on supersonic combustion modeling. J. Propul. Power 35, 451-465 (2019)

65. Wang, Y., Yao, W., Fan, X.: Real-gas effect accounted for by the principle of extended corresponding states in modeling supersonic kerosene jet. In: 2018 Joint Propulsion Conference, AIAA Propulsion and Energy Forum and Exposition. Cincinnati, Ohio, 9-11 July (2018)

66. Li, B., Lee, Y., Yao, W., et al.: Prediction of kerosene properties at supercritical pressures by artificial neural network. In: 2018 Joint Propulsion Conference, AIAA Propulsion and Energy Forum and Exposition. Cincinnati, Ohio, 9-11 July (2018)

67. Yao, W., Fan, X.: Development of zone flamelet model for scramjet combustor modeling. In: 21 st AIAA International Space Planes and Hypersonic Systems and Technology Conference. Xiamen, China, 6-9 March (2017)

68. Yao, W., Wang, J., Fan, E., et al.: IDDES study of the flow and combustion characteristics in a RP-3 fueled round-to-elliptical shapetransition supersonic combustor. In: the 9th Chinese National Conference on Hypersonic Science and Technology, Xi'an, 18-21 October (2016)

69. Yao, W., Li, X., Wu, K., et al.: Detached eddy simulation of an axisymmetric scramjet combustor fueled by Daqing RP-3 aviation kerosene. In: the 8th Chinese National Conference on Hypersonic Science and Technology, Haerbing, 25-27 November (2015)

70. Yao, W., Zheng, L., Zhang, H.: Modeling analysis on the silica glass synthesis in a hydrogen diffusion flame. Int. J. Heat Mass Transf. 81, 797-803 (2015)

71. Fureby, C., Chapuis, M., Fedina, E., et al.: CFD analysis of the HyShot II scramjet combustor. Proc. Combust. Inst. 33, 2399-2405 (2011)

72. Larsson, J., Vicquelin, R., Bermejo-Moreno, I.: Large eddy simulations of the hyshot II scramjet. Annual research briefs 2011, Stanford University (2011)

73. Cecere, D., Ingenito, A., Bruno, C., et al.: Advances in LES of the hyshot II scramjet combustor. In: Processes and Technologies for a Sustainable Energy, Ischia, June 27-30 (2010)

74. Antonella, I., Claudio, B., Donato, C.: LES of the hyshot scramjet combustor. In: 48th AIAA Aerospace Sciences Meeting Including the New Horizons Forum and Aerospace Exposition. Orlando, Florida, 4-7 January (2010)

75. Johan, L.: Large eddy simulation of the hyshot II scramjet combustor using a supersonic flamelet model. In: 48th AIAA/ASME/SAE/ASEE Joint Propulsion Conference and Exhibit. Atlanta, Georgia, 30 July-1 August (2012)

76. Romagnosi, L., Ingenito, A., Cecere, D., et al.: The role of the baroclinic term in supersonic fuel/air mixing enhancement. In: 49th AIAA Aerospace Sciences Meeting Including the New Hori- zons Forum and Aerospace Exposition. Orlando, Florida, 4-7 January (2011)

77. Cecere, D., Ingenito, A., Giacomazzi, E., et al.: Hydrogen/air supersonic combustion for future hypersonic vehicles. Int. J. Hydrogen Energy 36, 11969-11984 (2011)

78. Chapuis, M., Fedina, E., Fureby, C., et al.: A computational study of the hyshot II combustor performance. Proc. Combust. Inst. 34, 2101-2109 (2013)

79. Cocks, P.A.T.: Large eddy simulation of supersonic combustion with application to scramjet engines. [Ph.D. thesis]. Corpus Christi College, University of Cambridge (2011)

80. Ingenito, A., Runo, C.B.: Mixing and combustion in supersonic reactive flows. In: 44th AIAA/ASME/SAE/ASEE Joint Propulsion Conference \& Exhibit. Hartford, Connecticut, 21-23 July (2008)

81. Ingenito, A., De Flora, M.G., Bruno, C.: LES modeling of scramjet combustion. In: 44th AIAA Aerospace Sciences Meeting and Exhibit. Reno, 9-12 January (2006)

82. David, P., Graham, C.: Hybrid RANS/LES of a supersonic combustor. In: 26th AIAA Applied Aerodynamics Conference. Honolulu, Hawaii, 18-21 August (2008)

83. Peterson, D.M., Candler, G.V., Drayna, T.W.: Detached eddy simulation of a generic scramjet inlet and combustor. In: 47th AIAA Aerospace Sciences Meeting Including the New Horizons Forum and Aerospace Exposition. Orlando, Florida, 5-8 January (2009)

84. David, P., Erik, T., Graham, C.: Hybrid Reynolds-averaged and large-eddy simulation of scramjet fuel injection. In: 17th AIAA International Space Planes and Hypersonic Systems and Technologies Conference. San Francisco, California, 11-14 April (2011)

85. Aksu, T., Uslu, S.: Large-eddy simulation of a dual-mode scramjet combustor using non-adiabatic flamelet modeling. In: 55th AIAA Aerospace Sciences Meeting. Grapevine, Texas, 9-13 January (2017)

86. Zettervall, N., Fureby, C.: A computational study of ramjet, scramjet and dual-mode ramjet combustion in combustor with a cavity flameholder. In: 2018 AIAA Aerospace Sciences Meeting. Kissimmee, Florida, 8-12 January (2018)

87. Kim, S.H., Donde, P., Raman, V., et al.: Large eddy simulation based studies of reacting and non-reacting transverse jets in supersonic crossflow. In: 50th AIAA Aerospace Sciences Meeting Including the New Horizons Forum and Aerospace Exposition. Nashville, Tennessee, 10 January (2012)

88. Jung, C., Suresh, M.: Large-eddy simulation of cavity-stabilized supersonic combustion. In: 45th AIAA/ASME/SAE/ASEE Joint Propulsion Conference and Exhibit. Denver, Colorado, 2-5 August (2009)

89. Cai, Z., Wang, Z., Sun, M., et al.: Large eddy simulation of the flame propagation process in an ethylene fueled scramjet combustor in a supersonic flow. In: 21st AIAA International Space Planes and Hypersonics Technologies Conference. Xiamen, China, 6-9 March (2017)

90. Chaitanya, G., Jung, C., Srikant, S., et al.: Large eddy simulation of supersonic combustion in a cavity-strut flameholder. In: 49th AIAA Aerospace Sciences Meeting Including the New Horizons Forum and Aerospace Exposition. Orlando, Florida, 4-7 January (2011)

91. Jung, C., Chaitanya, G., Suresh, M.: Large-eddy simulation of cavity flame-holding in a Mach 2.5 cross flow. In: 48th AIAA Aerospace Sciences Meeting Including the New Horizons Forum and Aerospace Exposition. Orlando, Florida, 4-7 January (2010)

92. Sun, M.B., Geng, H., Liang, J.H., et al.: Mixing characteristics in a supersonic combustor with gaseous fuel injection upstream of a cavity flameholder. Flow Turbul. Combust. 82, 271-286 (2008)

93. Gottiparthi, K.C., Sankaran, R., Ruiz, A.M., et al.: Large eddy simulation of a supercritical fuel jet in cross flow using GPU- 
acceleration. In: 54th AIAA Aerospace Sciences Meeting. San Diego, California, 4-8 January (2016)

94. Gottiparthi, K.C., Sankaran, R., Oefelein, J.C.: High fidelity large eddy simulation of reacting supercritical fuel jet-in-cross-flow using GPU acceleration In: 52nd AIAA/SAE/ASEE Joint Propulsion Conference. Salt Lake City, UT, 25-27 July (2016)

95. Rajasekaran, A., Babu, V.: Numerical simulation of kerosene combustion in a dual mode supersonic combustor. In: 42nd AIAA/ASME/SAE/ASEE Joint Propulsion Conference and Exhibit. Sacramento, California, 9-12 July (2006)

96. Behera, R., Chakraborty, D.: Numerical simulation of combustion in kerosene fueled ramp cavity based scramjet combustor. J. Aerospace Sci. Technol. 58, 104-111 (2006)

97. Lacaze, G., Vane, Z., Oefelein, J.C.: Large eddy simulation of the hifire direct connect rig scramjet combustor. In: 55th AIAA Aerospace Sciences Meeting. Grapevine, Texas, 9-13 January (2017)

98. Liu, Y., Dowling, A.P., Swaminathan, N., et al.: Prediction of noise source for an aeroengine combustor. In: 17th AIAA/CEAS Aeroacoustics Conference. Portland, Oregon, 5-8 June (2011)

99. Clercq, P.L., Domenico, M.D., Rachner, M., et al.: Impact of fischer-tropsch fuels on aero-engine combustion performance. In: 48th AIAA Aerospace Sciences Meeting Including the New Horizons Forum and Aerospace Exposition, Orlando, Florida, 4-7 January (2010)

100. Cazalens, M., Rullaud, M., Frenillot, J.P.: Computational methodology for carbon monoxide emission for aeroengine combustor design. J. Propul. Power 24, 779-787 (2008)

101. Yang, J., Wu, X.Y., Wang, Z.G.: Parametric study of fuel distribution effects on a kerosene-based scramjet combustor. Int. J. Aerospace Eng. 7604279, 1-14 (2016)

102. Dharavath, M., Manna, P., Sinha, P.K., et al.: Numerical analysis of a kerosene-fueled scramjet combustor. J. Therm. Sci. Eng. Appl. 8, 0110037 (2016)

103. Zhang, M., Hu, Z., He, G., et al.: Large-eddy simulation of kerosene spray combustion in a model scramjet chamber. Proc. Inst. Mech. Eng. 224, 949-960 (2010)

104. Kumaran, K., Behera, P.R., Babu, V.: Numerical investigation of the supersonic combustion of kerosene in a strut-based combustor. J. Propul. Power 26, 1084-1091 (2010)

105. Zhang, M., Hu, Z., Luo, K.H., et al.: LES of kerosene spray combustion with pilot flame in a model dual mode ramjet chamber. In: 45th AIAA/ASME/SAE/ASEE Joint Propulsion Conference and Exhibit. Denver, Colorado, 2-5 August (2009)

106. Rajasekaran, A., Satishkumar, G., Babu, V.: Numerical simulation of the supersonic combustion of kerosene in a model combustor. Prog. Comput. Fluid Dyn. 9, 30-42 (2009)

107. Rajasekaran, A., Babu, V.: Evaluation of a ramp cavity based concept supersonic combustor using CFD. Prog. Comput. Fluid Dyn. 9, 16-29 (2009)
108. Kumaran, K., Babu, V.: Mixing and combustion characteristics of kerosene in a model supersonic combustor. J. Propul. Power 25, 583-592 (2009)

109. Manna, P., Behera, R., Chakraborty, D.: Liquid-fueled strutbased scramjet combustor design: a computational fluid dynamics approach. J. Propul. Power 24, 274-281 (2008)

110. Yamashita, H., Shimada, M., Takeno, T.: A numerical study on flame stability at the transition point of jet diffusion flames. Proc. Combust. Inst. 26, 27-34 (1996)

111. Hartill, W.B.: Analytical and experimental investigation of a scramjet inlet of quadriform shape. U.S. Air Force Report No. AFAPL-TR-65-74, Marquardt Corporation (1965)

112. Gruber, M., Smith, S., Mathur, T.: Experimental characterization of hydrocarbon-fueled, axisymmetric, scramjet combustor flowpaths. In: 17th AIAA International Space Planes and Hypersonic Systems and Technologies Conference. San Francisco, California, 11-14 April (2011)

113. Smith, S., Gruber, M., Steiner, R., et al.: Development and calibration of an axisymmetric direct-connect supersonic-combustion flowpath. In: 45th AIAA/ASME/SAE/ASEE Joint Propulsion Conference and Exhibit. Denver, Colorado, 2-5 August (2009)

114. David, P., Russell, B., Vincent, W.: Hybrid Reynolds-averaged and large-eddy simulation of mixing in an axisymmetric scramjet. In: 18th AIAA/3AF International Space Planes and Hypersonic Systems and Technologies Conference. Tours, France, 24-28 September (2012)

115. Houshang, E., Datta, G., Faure, M.M.: Exploratory RANS and LES simulations of transient supersonic combustor flow. In: 47th AIAA Aerospace Sciences Meeting Including the New Horizons Forum and Aerospace Exposition. Orlando, Florida, 5-8 January (2009)

116. Doherty, L.J., Smart, M.K., Mee, D.J.: Experimental testing of an airframe-integrated three-dimensional scramjet at Mach 10. AIAA J. 53, 3196-3207 (2015)

117. Suraweera, M.V., Smart, M.K.: Shock-tunnel experiments with a Mach 12 rectangular-to-elliptical shape-transition scramjet at offdesign conditions. J. Propul. Power 25, 555-564 (2009)

118. Smart, M.K.: Experimental testing of a hypersonic inlet with rectangular-to-elliptical shape transition. J. Propul. Power 17, 276-283 (2001)

119. Gollan, R., Ferlemann, P.: Investigation of rest-class hypersonic inlet designs. In: 17th AIAA International Space Planes and Hypersonic Systems and Technologies Conference. San Francisco, California, 11-14 April (2011)

120. Yue, W., Meneveau, C., Parlange, M.B., et al.: Turbulent kinetic energy budgets in a model canopy: comparisons between LES and wind-tunnel experiments. Environ. Fluid Mech. 8, 73-95 (2008) 